\title{
Targeted gene disruption coupled with metabolic screen approach to uncover the LEAFY COTYLEDON1-LIKE4 (L1L4) function in tomato fruit metabolism
}

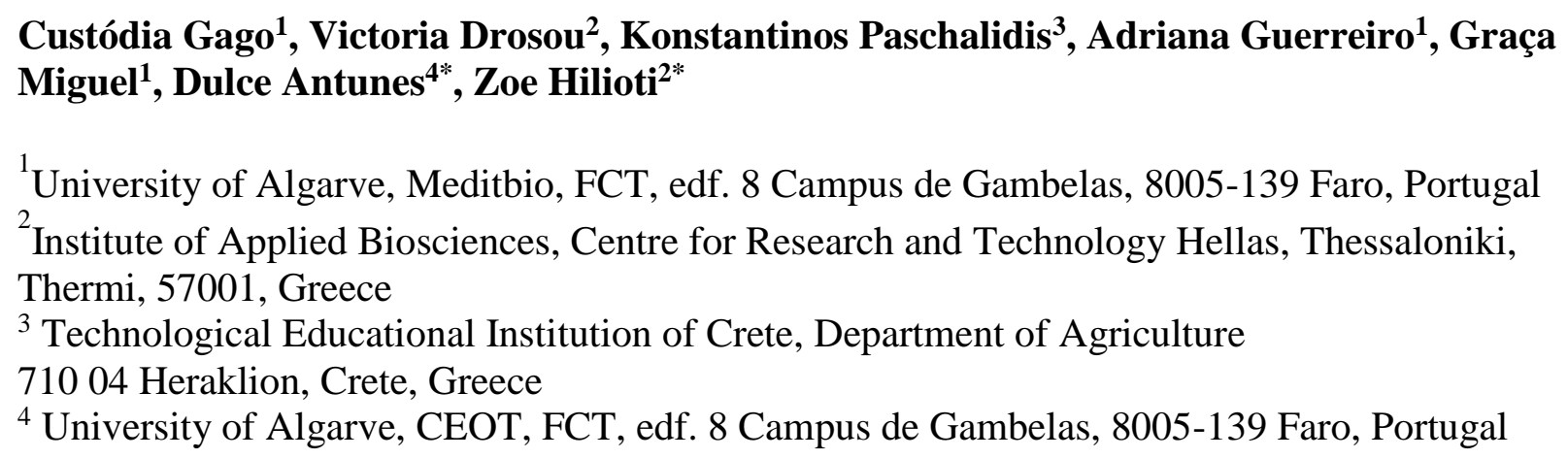


42 based analysis and physico-chemical methods in different L1L4 mutants of the fourth generation 43 allowed a comparative assessment of the effects of the TF disruption. Mutagenesis resulted in 44 fruits phenotypically similar to wild-type with subtle shape differences in the distal end 45 protrusion and symmetry. Conversely, mutant fruits from independent lines had significant 46 variation in moisture content, titratable acidity and overall metabolite profiles including oxalic 47 and citric acid, fructose, $\beta$-carotene, total polyphenols and antioxidants. Lines 6,7 and 9 were the 48 richest in $\beta$-carotene and antioxidant activity, line 4 in ascorbic acid and lines 4 and 8 in succinic 49 acid. The reduced content of the anti-nutrient oxalic acid in several mutant fruits suggests that $50 \quad$ L1L4 gene may regulate the accumulation of this compound during fruit development. Detailed 51 LC-MS/MS analysis of mutant seeds showed substantial differences in bioactive compounds 52 compared to wild-type seeds. Taken together, the results suggest that the L1L4 TF is a 53 significant regulator of metabolites both in tomato fruit and seeds providing a molecular target 54 for crop improvement. Elucidation of the candidate genes encoding key enzymes in the affected 55 metabolic pathways aimed at facilitating a better exploration of the L1L4 gene networks and to 56 expedite the use of systems biology approaches in tomato fruit.

\section{KEY MESSAGE}

60 Functional analysis of tomato L1L4 master transcription factor resulted in important metabolic 61 changes affecting tomato fruit quality.

\section{INTRODUCTION}

64 Tomato (Solanum lycopersicum L.) is an important fresh produce crop. The fruit is produced in 65 large scale and consumed all over the world. World's tomato production reached 137 MT in 662012 (http://faostat.fao.org) ranking it as one of the most economically important horticultural 
67 crops. Tomato fruit for consumption, as either fresh or processed, is an important source of 68 nutrients, such as vitamins, carotenoids and phenolics (Antunes, et al. 2013; Breksa, et al. 2015;

69 Odriozola-Serrano, et al. 2008). Sugars and organic acids and their balance are the main 70 contributors to the tomato's fruit taste. In particular, ascorbic acid (vitamin C) along with the 71 carotenoids lycopene and $\beta$-carotene and phenolic compounds (flavonoids and hydroxyxinnamic 72 acids) are responsible for the tomato antioxidant properties which are health promoting 73 phytochemicals in human diet (Ilahy, et al. 2011). Therefore, enhancing the tomato fruit quality 74 is of great research interest for both nutraceutical and horticultural industries (Rigano, et al. 75 2013; Rosati, et al. 2000).

77 Appropriate cultivars must be selected to reach the demand of growers and consumers. Markets 78 are today interested in differentiating products by attributes related to taste, aroma, acidity, sugar 79 content and vitamins (Causse, et al. 2002; Powell, et al. 2012; Serrano-Megías and López80 Nicolás 2006). Traditionally, tomato breeding has been focused on the improvement of yield, 81 disease resistance, tolerance to abiotic stress and sugar content [(López, et al. 2015) and 82 references therein]. Yield enhancement was achieved by crosses with wild relative species 83 (Swamy and Sarla 2008). However, many quantitative trait loci (QTL) for yield and related traits 84 as fruit weight, total soluble solids or lycopene content were found non-randomly distributed in 85 the genome (Fulton, et al. 1997; Fulton, et al. 2000; López, et al. 2015). Domestication and 86 breeding of tomato plants resulted in a variety of phenotypes with increased fruit weight, 87 variability in fruit shape and color (Paran and van der Knaap 2007), as well as differences in fruit 88 quality characteristics which have been largely attributed to genetic factors (Breksa, et al. 2015; 89 Choi, et al. 2014). Phenotypic tomato fruit diversity may range from round to elongated and from 
90 small to large. Thus far, the elongated shape was linked to the loci sun (Van der Knaap, et al. 91 2004; Van der Knaap and Tanksley 2001), ovate (Ku, et al. 1999; Liu, et al. 2002; Van der

92 Knaap, et al. 2002) and fs8.1 (Grandillo, et al. 1996; Ku, et al. 2000).

93

94 The downside of the conventional breeding approaches is that they remain a time-consuming (99515 years for cultivar improvement) and laborious effort considering the relatively long life cycle 96 of tomato (90-120 d) and the fact that, most of the times, these approaches are not targeted to a 97 single genetic locus. As a result of this, classic research in tomato has characterized only a few 98 mutants at molecular level. Recent efforts to increase the available resources for tomato research 99 centered on tomato Heinz 1706 genome sequencing project which after its completion (Tomato 100 Genome 2012), provided clues for fruit evolution and fueled functional genomics studies in this 101 species. The advantages of tomato Heinz 1706 are its compact growth, high production, 102 determinate growth pattern and adaptability to both controlled environments and field conditions. 103 The molecular-based breeding in tomato could be accelerated by using gene targeting 104 technologies, such as the Zinc Finger Nuclease (ZFN) technology, to identify genes required for 105 a particular trait. In our previous studies in tomato, we found that $L 1 L A$, a member of the $L 1 L$ 106 gene family, was expressed in flowers and green developing fruit (Hilioti, et al. 2014) while a 107 ZFN-based disruption of the coding sequence of the TF affected fruit phenotype (Hilioti, et al. 108 2016). Notably, the L1L4 (or $N F-Y B 6$ ), encodes the B subunit of CCAAT binding heterotrimeric 109 transcription factor NF-Y, an embryo-specific transcription factor involved in plant development 110 and regulation of seed storage proteins and fatty acid biosynthesis (Kagaya, et al. 2005; Lotan, et 111 al. 1998; $\mathrm{Mu}$, et al. 2008). 
113 We studied the function of L1LA TF in tomato fruit development and quality and evaluated both 114 fruit tissues and seeds in an effort to establish a relationship between metabolites in fruits and 115 seeds of each mutant line. The integrative analyses allowed us to identify crucial content 116 variation in major metabolites which was attributed to the regulatory role of L1L4.

\section{7} 118

\section{RESULTS AND DISCUSSION}

\section{Selection of different $L 1 L 4$ disruption variants}

Tomato, apart from being an economically important food crop, serves as a model system for complex processes, such as fruit development, ripening (Giovannoni 2004) and seed development (Hilhorst, et al. 1998). In a previous study, we used ZFN technology to target the developmental TF L1L4. Disruption of L1L4 coding sequence revealed that the TF is a global regulator of tomato development, affecting flower fruit setting, fruit and seed morphology (Hilioti, et al. 2016). In the current study, plants homozygous for $L 1 L 4$ of the $\mathrm{M}_{4}$ generation were produced, as the cultivar Heinz 1706 displays cleistogamy and is self-pollinated. Independent plants from each mutant line were studied for fruit quality. In Arabidopsis, LEC1/LIL is an essential gene regulating plant development (Kwong, et al. 2003). HRM analysis was used to identify 8 lines carrying different ZFN-induced and NHEJ-mediated mutations (indels) in the target locus (Figure 1A). The presence of indels in the target locus produced different melting curves compared with the one from the non-mutated amplified target DNA flanking the end of exon 1 and beginning of exon 2. Sequencing of the L1L4 locus amplified from cDNA by PCR using a forward and a reverse primer in exons 1 and 2, respectively, revealed the exact genotypes of the mutant lines (Figure 1B). Interestingly, nucleotide changes were found in lines 2 and 4 while lines 5 and 7 have a 1-bp insertion which results in frameshift. Line 3 had a 2-bp deletion 
137 and line 6 had two 1-bp insertions in addition to nucleotide changes. Line 8 had nucleotide 138 changes and deletions while line 9 had a 1-bp deletion and insertion at the end of exon 1 . The 139 unique coding sequence polymorphism in mutant lines lied upstream of the DNA binding 140 domain of the TF and the highly conserved among eukaryotes central region of NF-YB subunit 141 (Li, et al. 1992; Mantovani 1999). Unlike other TFs, three subunits (NF-YA, NF-YB and NF142 YC) of NF-Y are required to create the DNA binding domain (Maity and de Crombrugghe 1992; 143 McNabb, et al. 1995; Sinha, et al. 1995). Therefore, one would expect that L1L4 mutations could 144 potentially affect one or more of the following: the recognition ability of L1L4 to target the 145 promoters of its target genes, the interaction of the L1L4 protein with the NF-YC subunit, and 146 NF-Y complex formation. In the last two cases the effect of the mutation would lead to a 147 functional knockout. Substitutions and other specific characteristics of the L1LA mutations in 148 coding region were revealed by comparison with the wild-type sequence via multiple sequence 149 alignment (Supplemental File 1). Indels in lines 3, 5 and 7 led to premature nonsense (stop) 150 codons in L1L4 and in truncated proteins lacking the central B and C-terminal C domains of the 151 transcription factor (Supplemental File 1). The truncated versions of the TF are expected to be 152 non-functional. However, a well-conserved domain is present in the truncated isoforms and other 153 mutants from residues 1 to 19 , where potential phosphorylation sites for serine may be present. If 154 the truncated proteins are stable and substrates for phosphorylation, then they can compete with 155 other substrates causing interference in other phosphorylation-dependent pathways. In line 2 , 156 nucleotide substitution mutations led to E34N, L35R, P36H amino acid substitutions, which are 157 also rare as the exchanged residues have very different structures and properties. Mutant line 4 158 constitutes a unique case as it carries a single amino acid substitution of aspartic (abbreviated as 159 Asp or D) to tyrosine (abbreviated as Tyr or Y) residue at position 23. The D23Y substitution is 
also fixed in line 9, in addition to the presence of three more amino acid substitutions (T20P, P21L, A22Q) in this line. The aspartic acid to tyrosine substitution is rare as the two amino acids have very different structures, properties and biological functions. An Aspartic acid residue is negatively charged prefers to be on the surface of proteins, and it can be a phosphomimetic chemically similar to phospho-serine. From the other hand, Tyr residue is aromatic and prefers to be buried in protein hydrophobic cores. This replacement is expected to maximally alter the hydrophofic surface of L1L4 and consequently the accessibility of kinases to possible serine residues located nearby Tyr-23, altering, in such scenario, L1L4 protein regulation. Further, it is possible that tyrosine itself is a target for phosphorylation by tyrosine-specific kinases and this phosphorylation is crucial for a signal transduction process in the cells. Line 6 carries a block of six different amino acid residues (EPGTDN) compared to wild-type (ELP) in the amino acid region between 33 and 38, which is expected to alter the folding and properties of the protein. Notably, the Ser-32, which is quite conserved in other lines, has been substituted with glutamic acid (E) in this line. The insertion and deletion of nucleotides in line 8 changed the reading frame only of the region between P20-L40, resulting in a completely different translation from the wild-type. Overall, the amino acid substitutions in L1L4 appeared between the residues 20 and 38 of the protein, which suggests that the region is under relaxed selection and mutations can be tolerated.

\section{Consequences of $\mathrm{LILA}$ disruption on tomato fruit appearance}

Fruit quality, as determined by the appearance of the fruit including its shape, size, color, synchronous ripening and absence of defects, remains an important quality criterion for fresh market industries. To investigate the tomato fruit morphological effects of the L1LA coding sequence disruption, we assessed the variation of shape in fertile lines carrying different L1LA 
190

mutations in relation to the wild-type species. Based on visual observation, the phenotype of the fruits from mutant lines showed subtle shape differences in the distal end protrusion and symmetry (Figure 2), which did not significantly affect the size of the fruit in terms of diameter, length and weight (Table 1). In contrast to wild-type plants that produced elongated and threeloculed fruit, L1L4 mutant fruits had usually not more than two locules (data not shown). Previous studies have linked mutations in the LOCULE NUMBER (LC) (Barrero, et al. 2006) and FASCIATED ( $f$ or fas) genes (Lippman and Tanksley 2001) to the increase in locule number of tomato fruit. Further, the characteristic distal end protrusion of Heinz 1706, which is related to localized cell division events, was either more or less pronounced in mutants compared to wildtype (Figure 2). Specifically, lines 2, 3, 4, 8 and 9 showed a pronounced distal end protrusion compared to wild-type. This suggested that the fruit shape trait is under LILA TF control while the genes regulated by this TF remain to be identified. A previous study in tomato determined that mutations in the $S U N, O V A T E, L C$ and/or $F A S$ genes can explain as much as $71 \%$ of the fruit shape diversity (Rodríguez, et al. 2011). In particular, SUN gene product has been hypothesized to control elongated fruit shape by acting as positive regulator on growth to alter hormone or secondary metabolite levels (Xiao, et al. 2008).

Tomato color correlates with maturity and the $\mathrm{a} / \mathrm{b}$ ratio, which measures the relative amounts of red (a) and yellow (b), has been used as an indicator of maturity (Arias, et al. 2000). The results of this study revealed that tomato color was almost not influenced by L1LA gene disruption (Figure 2). In addition, color parameters $\mathrm{L}$ and $\mathrm{a}^{*}$ had similar values among all tomato lines (Table 1) except line 3 (Table 1). Nevertheless, none significantly differed from wild-type fruit at the ripe stage. 
207

208

8

Fruit weight ranged from $29.35 \mathrm{~g}$ (line 3) to $40.51 \mathrm{~g}$ (line 4) showing a 1.4-fold variation from lowest to highest weights, being significantly different only between lines 3 and 4 . Nevertheless, fruit diameter and length did not show significant differences among lines and wild-type (Table 1).

213 Although consumers buy on the basis of appearance and textural quality, their satisfaction and 214 repeat purchases are dependent upon good eating (flavor) quality. Firmness was also not affected 215 by the L1L4 gene disruption, being all lines and wild-type with values which did not significantly 216 differ (Table 1).

\section{7 \\ 218 Fruit compositional changes related to $L 1 L 4$ gene disruption}

219 Tomato ripening is a highly regulated developmental process involving changes in fruit color 220 and alterations in its texture-a result of cell wall remodeling-as well as changes in metabolism in 221 terms of accumulation of sugars, organic acids, flavonoids, carotenoids and ascorbic acid which 222 can influence the flavor quality of the fruit. An autocatalytic increase in respiration and ethylene 223 biosynthesis precedes the initiation of ripening in tomato while a number of transcription factors 224 encoded by the NON-RIPENING (NOR), COLORLESS NON-RIPENING (CNR), and RIPENING 225 INHIBITOR $(R I N)$ regulate the ripening process in concert with the gas hormone ethylene 226 [reviewed in (Giovannoni 2007)].

228 To determine whether fruit quality characteristics were different in L1L4 mutant tomato lines and 229 wild-type, several attributes were evaluated. Tomato firmness is a texture attribute that 230 determines postharvest shelf-life and is required for shipping to distant markets. Maintenance of 
firmness was observed in all mutant fruits with values which did not significantly from the wildtype (Table 1). In contrast to fruit firmness, a strong variation in fruit soluble solids content (SSC) was detected for the mutants in Heinz 1706 background with values between 3.6 and $4.68 \%$ (Table 1), which were greater than the range (3.57 to 3.75) of SSC values reported by Ferreira (Ferreira 2001) and lower than that (5.18 to 7.88) of the Mexican cultivars (Mahakun, et al. 1979). Importantly, all mutant fruits had increased SSC when compared to wild-type. SSC content is of prime importance in fresh-market tomatoes and a breeding target (Stevens 1986), as it affects flavor (Simandle, et al. 1966) and nutritive value. An increase in SSC is also desirable in processing tomatoes and it has been estimated that an increase of $1 \%$ in fruit SSC represents a $20 \%$ increase in yield of processed product (e.g. paste, purees) which translates in significant financial profit (Wood 1992). In line 4, the single D23Y substitution was sufficient to increase SSC content over wild-type levels while the additional substitutions present in line 9 did not contribute significantly to SSC content. The SSC contents in lines 3 and 5 carrying the truncated forms of the TF were similar to those in lines 4 and 9 carrying amino acid substitutions between residues 20 and 23 . The acidity of the fruit is very important for the flavor and storability of processed tomato. Genetic factors are the major acid content determinants in tomato fruits, with great variation occurring among genotypes (Stevens and Rick 1986). Fruit titratable acidity (TA) varied greatly in the mutant lines with line 9 having the highest value which did not significantly differ from lines 4, 6 and 7, while wild-type had the lowest value which was similar to lines 2, 3, 5 and 8 (Table 1). Specifically, TA values ranged from 0.49 to 0.68 (wild-type) and were similar to values reported for the Mexican tomato cultivars (Méndez I, et al. 2011). The single D23Y substitution in line 4 was sufficient to reduce significantly the TA in fruits. Taste is one factor that affects perception of flavor. The taste index was calculated using the values of SSC and TA 
254 and applying the equation determined by Navez et al. (Navez, et al. 1999). The mutants had values between 0.89 and 1.0 (Table 1), thus being adequate for fresh consumption. According to Navez et al. (Navez, et al. 1999) if the value of the taste index is higher than 0.7, tomato is considered as tasty. Lines 3 and 8 had the lowest values (0.89 and 0.90 , respectively), in contrast to line 7, with the highest value (1.0) (Table 1). Fruit moisture (Table 2) ranged from 93.2 (line 9) to $95.34 \%$ (wild-type), which was similar in magnitude to the values obtained by some tomato cultivars grown in Tenerife (Suárez, et al. 2008). Fruit fiber content is another important quality characteristic that was affected in lines 4,5 and 8 with values significantly greater than in wildtype (Table 2), while wild-type values were similar to the ones obtained for other tomato cultivars (Suárez, et al. 2008). These results indicate that L1L4 regulates fiber content in tomato which is a beneficial health parameter.

Tomato mutant lines investigated in this work did not show variation in ash content (Table 2). On the contrary, great variation in the crude protein content (free and protein-bound amino acids) was detected in the mutants with values from $0.48 \%$ (line 2) to $0.81 \%$ (wild-type) (Table 2). Mutations in lines 2, 3, 4 and 9 resulted in significantly lower protein content than wild-type and lines 6, 7 and 8. The crude protein content of the wild-type background was similar to Korean 271 cherry tomato fruits (Choi, et al. 2014).

273 Fruit flavor is greatly affected by sugars as they contribute to sweetness. The sugars glucose and 274 fructose are the most prominent fractions of the SSC in the domesticated tomato (S. 275 lycopersicum). On the contrary, some wild tomato species (e.g. S. chmielewskii) accumulate mostly sucrose (Yelle, et al. 1991). The soluble sugar contents (glucose, fructose and sucrose) 
were determined in mature fruit tissues. As anticipated from previous studies, fructose was present in high concentration followed by glucose, in agreement with results in other tomato cultivars (Antunes, et al. 2013; Breksa, et al. 2015). Remarkably, the fructose to glucose ratio was lower (1.3) in wild-type than in the LILA mutants ( $\geq 1.5)$ (Table 2). The remarkably contrasted 'high-fructose-to-glucose' phenotype that contributes to sweetness in mutant lines suggests that the TF regulates fruit fructose content. The mechanism of this effect is not obvious, but needs to be further investigated in tomato fruits from individual lines. Overall, SSC showed a significant and positive correlation with the fructose concentration $(r=486, p<0.01)$. Fruit flavor is also affected by the degree of sourness and the level of citric acid. Among the identified fruit acids in the current study, citric acid level was significantly reduced in 5 out of 8 mutant lines, with values ranging from 7.66 to $21.88 \mathrm{~g} / \mathrm{kg} \mathrm{DW}$, which reflects a reduction in wild-type levels by 64.8 and $26.66 \%$, respectively (Table 2). The persistence of the dramatic reduction in citric acid levels in mutant fruits provided compelling evidence for the involvement of the TF in the regulation of citric acid production.

The presence of oxalic acid in tomato has been previously reported (Islam, et al. 1996; Suárez, et al. 2008). The plant metabolite oxalic acid when present in relative high amounts can be considered as an anti-nutrient because it may inhibit the correct absorption of calcium due to the formation of insoluble salts with calcium, particularly if the ratio of oxalic acid to $\mathrm{Ca}$ is higher than 2.25. In such cases, food is considered to be decalcifying (Suárez, et al. 2008). In the present study, oxalic acid was reduced in lines 2 and 5 by $70-80 \%$ of wild-type levels, although it was also reduced in lines 3, 4, 6 and 9 to a smaller extent (Table 2). A reduction in the levels of oxalic acid in tomato fruit is desirable as it may facilitate the absorption of micronutrients. 
300

301

8

Ascorbic acid, vitamin C, is a powerful antioxidant and a low intake may result in adverse health effects. Tomato fruits from line 4 showed the highest ascorbic acid content with a 2.7 -fold increase above wild-type level. On the contrary, ascorbic acid was not detectable in line 5. Since ascorbic acid is an essential dietary component, line 4 could be used for breeding cultivars enriched in ascorbic acid. Further, line 6 exceeded in quinic acid content by 1.72-fold the wildtype level, while quinic acid was not detected in line 2 (Table 2). Shikimic acid concentrations increased over wild-type levels in 6 out of 8 LILA mutant lines. Although succinic acid was not detected in wild-type fruit, L1L4 lines produced fruits with increased levels $(0.16-1.25 \mathrm{~g} / \mathrm{Kg}$ DW) of succinic acid, which provides a foundation for developing tomato fruit as a system for producing succinic acid. Succinic acid has a specialty chemical market which includes surfactants, detergents, foods and pharmaceuticals (Zeikus, et al. 1999). Specifically, mutant lines 8 and 4 had the highest succinic acid content. Succinic (Suárez, et al. 2008) and shikimic acids (Osvald, et al. 2001) were also previously reported in tomato samples. The sum of the 6 acids content, herein identified, showed a negative correlation with tomato fructose concentration $(\mathrm{r}=-0.535, \mathrm{p}<0.01)$.

317 The content of antioxidants in tomato fruits from wild-type and mutant lines growing under 318 controlled conditions in the greenhouse was also investigated. Total phenol content was 319 consistently higher in all of the L1L4 mutant tomatoes, as compared to the wild-type (Table 3). 320 Line 9 had the highest phenol content which was 1.48-fold higher than the wild-type level. Our 321 results for phenol content in mutant lines are consistent with the results from Toor et al. (Toor and Savage 2005) ranging from 7.41 to $21.7 \mathrm{mg} \mathrm{GAE} / \mathrm{kg} \mathrm{FW}$, which indicates that the genotype 
323 significantly affects total phenol content in tomato (Dumas, et al. 2003; George, et al. 2004). According to Toor et al. (Toor and Savage 2005), flavonoids represent the major component of the total phenol content in tomato fruit. No differences were detected in flavonoid content among mutant lines. Tomato fruit is an important source of carotenoids in the human diet (Beecher 1998). The $\beta$-carotene levels were higher (approximately 3.5-fold increase) in lines 6,7 and 9 compared to wild-type (Table 3), with concentrations ( 0.5 mg/100 g FW) consistent with those reported on tomato cultivars from Italy (Ilahy, et al. 2011) and China (Juroszek, et al. 2009). Lycopene, a carotenoid, is the most prominent (90-99\%) (Dumas, et al. 2003) lipophilic pigment in tomato fruits known for its strong antioxidant role associated with its ability to act as free radical scavenger (Müller, et al. 2011). Lycopene levels in mutant lines did not differ significantly from wild-type levels. Nevertheless, lycopene values observed were higher than the ones described for fresh tomatoes from China (Chang, et al. 2006), but slightly lower than in Italian varieties $(\sim 10 \mathrm{mg} / 100 \mathrm{~g} \mathrm{FW})$ (Ilahy, et al. 2011). The general correlation between lycopene and $\mathrm{a}^{*} / \mathrm{b} *$ ratio, a measure of redness, has been noted previously (Arias, et al. 2000) and it was also found in this study $(\mathrm{r}=0.675, \mathrm{p}<0.05)$. The metabolites listed above (phenols, flavonoids, lycopene, $\beta$-carotene) have the ability to inhibit or retard oxidation processes which are associated with human aging and development of pathologies such as metabolic syndrome, cancer or degenerative disorders (Hamid, et al. 2010). In this context, lines 6 and 9 are of better quality concerning those quality characteristics. The antioxidant activity of the wild-type tomato fruits, determined by both the TEAC and the ORAC methods, was lower, as compared to the mutants. According to Dumas et al. (Dumas, et al. 2003) and Atanassova et al. (Atanassova, et al. 2007) the antioxidant contents in tomato fruit vary in relation to genotype and environment. As all mutant lines were grown under similar conditions, the higher antioxidant content was 
attributed to L1L4 gene disruption. Positive correlations were found between these antioxidant activities (ORAC) and the contents of all bioactive compounds referred above but they were only significant for total phenolics $(r=0.598, p<0.001)$ and $\beta$-carotene contents $(r=0.581, p<0.01)$.

Principal component analysis (PCA) was used to explore the similarities among all the lines with respect to the analyzed quality parameters. The data showed that three principal components explained $67 \%$ of the total variation (Figure 3A). The first, second and third components explained $31.16 \%, 21.0 \%$ and $14.84 \%$, respectively, of total variation. Variable analysis made possible to group the tomato lines in 3 groups in order to express and show the similarities and differences (Figure 3). Group I consisted of wild-type alone characterized mainly by the protein and moisture contents. Group II consisted of lines 2, 3, 4 and 8 which were closer because of their similarity in fiber, color values $\left(\mathrm{a}^{*}, \mathrm{~b}^{*}, \mathrm{C}^{*}\right.$ and hue), $\mathrm{pH}$, ascorbic and succinic acids content. Finally, group III consisted of lines 5, 6, 7 and 9 due to similarities in antioxidant activity, lycopene, $\beta$-carotene, glucose, shikimic acid content, $\mathrm{a}^{*} / \mathrm{b}^{*}$ ratio and fruit dimensions. A dendrogram confirmed the results of PCA (Figure 3B). The results of PCA further confirmed the previous analyses showing that the fruit quality parameters varied considerably with the L1L4specific mutations. Based on the overall results in fruit composition from lines 3, 5, and 7 carrying truncated and non-functional L1L4 proteins, the TF appears to be a negative regulator of fiber, fructose, succinic and shikimic acid biosynthesis and a positive regulator of citric and oxalic acid biosynthesis.

Hence, the single gene mutation breeding accompanied by fruit quality assessment provided a unique link between genotype, phenotype and fruit quality, which is currently missing for tomato 


\section{Profiling of metabolites in seeds based on LC-MS/MS analysis}

372 Tomato seeds represent a major (about 40\%) byproduct of the tomato processing industry. The 373 seeds contain about 34\% oil (Giannelos, et al. 2005) and posses antioxidant properties (Toor and 374 Savage 2005). To further address the role of L1L4 TF in seed metabolism, we screened, in 375 parallel, seeds from the same mutant fruits and wild-type for metabolites. The rational of this approach was that L1L4 may have some effect on known or unknown metabolites predominantly present in seeds. Notably, studies on tomato seed composition remain rather scarce; hence, our analysis contributes new knowledge to what is already known from previous studies (Hilhorst, et al. 1998; Mounet, et al. 2007; Persia, et al. 2003; Voelker and Kinney 2001). Typically, ripefruits from mutants and wild-type tomato plants were harvested, and the seeds were then analyzed by LC-MS/MS for the presence of carotenoids, flavonoids and non-volatile acids. The untargeted analysis, revealed a decrease in the levels of apigenin in mutant seeds compared to wild-type (Figure 4). Further, a pronounced reduction in luteolin levels was detected in all mutant seeds while the metabolite was practically undetectable in line 7 . These results suggest that L1L4 may regulate luteolin levels in tomato seeds. Luteolin was previously detected in tomato fruits (Chassy, et al. 2006), seeds and skins (Kalogeropoulos, et al. 2012). Apigenin and its derivatives have been previously identified in bell pepper (Miean and Mohamed 2001) and tomato products (Vallverdú-Queralt, et al. 2011), but to the best of our knowledge, this metabolite has not been reported previously for tomato seeds. The flavone apigenin and its structural analogue luteolin are known to have anti-inflammatory (Hougee, et al. 2005; Rezai- 
Zadeh, et al. 2008), free radical scavenging properties (Yao, et al. 2004) and cancer-preventing effects in humans (Chen, et al. 2006; Le Marchand 2002).

Citric acid is the predominant organic acid in tomato fruits (Davies 1966) and contributes to the total acidity. A comparison of flavonol profiles in wild-type and mutant seeds showed that the accumulation of citric acid and citric acid derivative were severely affected by the disruption of the TF. Specifically, citric acid derivative rose above wild-type levels in mutant seeds except in line 5. On the contrary, the levels of citric acid were dramatically decreased in all mutant seeds compared to wild-type. These results uncover a potential regulatory role for the TF in citric acid biosynthesis and conversion to organic derivatives in seeds, in addition to its role in regulating citric acid in tomato flesh (Table 2). Previous studies have determined that the processes involved in the metabolism and accumulation of citric acid are under both genetic and environmental control (Etienne, et al. 2013), while during tomato ripening citric acid levels increase (Anthon, et al. 2011).

407 species. They are health promoting components as a result of their antioxidant activities. In 408 tomatoes, $p$-coumaric acid, caffeic acid and ferulic acid are the most abundant hydroxycinnamic 409 acids (Luthria, et al. 2006) contributing to the beneficial and health promoting effects of tomato 410 products. LILA mutations led to dramatically decreased levels of $p$-coumaric acid in lines 3 and 4 411 while it was nondetectable in lines $2,5,6,7,8$ and 9, pointing to a regulatory role of L1L4 in $p$ 412 coumaric accumulation. Similarly, in all mutant seeds except those in line 6, the level of caffeic 
Compared with wild-type, the L1L4 mutants showed a decrease in the level of glucaric acid in 417 seeds, with the exception of line 3 where an increase was detected. Notably, glucaric acid content 418 in seeds from lines 2, 4, 7 and 8 was reduced to $40 \%$ of wild-type level. Glucaric acid is formed 419 by the oxidation of glucose. The metabolite has been detected in camelina seeds, another oilseed 420 crop (Li, et al. 2015). D-glucaric acid (or saccharic acid) and its derivatives, normally present in 421 fruits and vegetables (Dwivedi, et al. 1990), have been associated with therapeutic uses including 422 cholesterol reduction (Walaszek, et al. 1996), diabetes treatment (Bhattacharya, et al. 2013) and 423 cancer prevention (Walaszek 1990).

\section{3 biosynthesis.}

Homoveratric acid, a biophenol compound, has been detected previously in tomato (GómezRomero, et al. 2010) and olive millwaste (Obied, et al. 2007). In the present study, the level of homoveratric acid was reduced in mutant seeds of lines 4 and 8 while it was increased above wild-type levels in seeds of lines 3, 5, 6 and 9. Only lines 2 and 7 maintained wild-type levels of homoveratric acid.

Overall, it became evident that the single D23Y substitution present in line 4 was sufficient to lower most of the seed metabolites examined, suggesting a negative interference in their 
435 Hence, the parallel investigation of ZFN-based targeted L1L4 mutations revealed the significant role of the TF in regulating tomato fruit quality while the effects on appearance were subtle in the selected mutant lines and mostly related to the distal end protrusion and symmetry. Fruits from lines 5, 6, 7 and 9 of the PCA group III, had good nutritional properties in terms of antioxidant activity, though with a reduced protein content. Importantly, an improved cultivar pertains not only to enrichment in nutrients but also to the low content of metabolites recognized as anti-nutrients such as oxalic acid. In this context, our study links for first time L1L4 function to oxalic acid accumulation in tomato fruits.

\section{In silico reconstruction of putative biosynthetic pathways of L1L4-dependent metabolites}

Due to the importance of tomato in human nutrition, we examined the in silico reconstruction of selected portions of specific biosynthetic pathways involved in tomato metabolism as identified by the analysis of metabolic profiles among the L1L4 mutant lines. In particular, the citrate, galactose, ascorbate and carotenoids contents were significantly affected in several mutant lines, suggesting a transcriptional regulation of the corresponding biosynthetic pathways by the TF.

Based on the current data, we initially employed a reductionist computational approach supported by the PMN software and the current biochemical knowledge to reconstruct three putative metabolic pathways for the production of $\beta$-carotene, L-ascorbate and succinate by determining the initial and end compound. A model of the metabolic pathways is shown in Figure 5. The L-ascorbate pathway (L-galactose pathway) has only been recently proposed in plants (Wheeler, et al. 1998) and uses D-glucose as metabolic input. In our model, L-ascorbate is formed from D-glucose in ten steps by Hexokinase (HXK), glucose-6-phosphate isomerase (EC 5.3.1.9), mannose-6-phosphate isomerase (EC 5.3.1.8), phosphomannomutase (EC 5.4.2.8), mannose-1-phosphate guanylytransferase (GDP, EC 2.7.7.22), GDP-mannose 3,5 epimerase (EC 
5.1.3.18), GDP-L-galactose phosphorylase (EC 2.7.7.69), sugar-phosphatase (EC 3.1.3.93), Lgalactose dehydrogenase (EC 1.1.1.316) and L-galactonolactone dehydrogenase (EC 1.3.2.3).

Further investigation on metabolic genes putatively involved in the above pathways will enable the engineering of tomato metabolite accumulation rationally in order to produce fruits with specific nutritional compositions. The great diversity of metabolites produced in fruits as well as the presence of gene families involved in metabolite biosynthesis pose limitations in the holistic representation of the fruit system. Current techniques for reconstructing metabolic networks have depended heavily on sequence homology searches (Bono, et al. 1998). PMN searches of genes coding for key enzymes in the selected metabolic pathways against the entire tomato genome enabled us to identify 31 gene models of S. lycopersicum fruit metabolism (Figure 5). Notably, most of the predicted genes in the gene models are not functionally characterized in tomato while multi-gene copies exist as in the case of mannose-1-phosphate guanylytransferase (Solyc03g096730.2.1, Solyc03g113790.2.1, Solyc09g011220.2.1, Solyc06g051270.2.1). Another gene family encoding HXK has been previously characterized in tomato (Dai, et al. 2002; Kandel-Kfir, et al. 2006; Menu, et al. 2001). Interestingly, in the HXK gene family only LeHXK4 was expressed in young fruits (Kandel-Kfir, et al. 2006). Genes that are directly regulated by L1L4 TF should be enriched for the CCAAT consensus LEC1 (CBF) binding element in their 477 promoters. The biological validity of the computational prediction of gene candidates shown in 478 Figure 5 will be verified in future experiments using L1L4 mutant backgrounds.

\section{CONCLUSIONS}


481 Targeted genome technologies are a young field in metabolic engineering of plants. The results of the current study in tomato fruits attempt to fill this gap in knowledge by demonstrating that ZFN-mediated targeted disruption of the master developmental regulator $L 1 L 4$ affects major fruit and seed metabolites which were hard to predict. The mutations were found between the residues 20 and 38 of L1L4 protein, which suggests that the region is under relaxed selection and mutations can be tolerated. This in turn, generates novel insight on L1L4 function in fruit quality. The identification of identical phenotypes (e.g. metabolic and morphologic) in several mutant fruits shows the robustness of the ZFN technology. The current data establish a relationship between high-order regulators of gene expression and physiological-metabolic phenotypes of tomato fruit. L1L4 TF appears to be a negative regulator of fiber, fructose, succinic and shikimic adic biosynthesis and a positive regulator of citric and oxalic acid. The single gene-based variations in metabolite composition may direct breeding for specific nutritional and/or antinutritional needs, such as fruits with high fructose content or low oxalate for diabetic diets. While L1L4 mutagenesis effect on fruit quality may be specific to tomato, it may be common or provide guidance for other fleshy-fruited plants.

\section{MATERIALS AND METHODS}

\section{$498 \quad$ Plant material}

499 Tomato seeds of S. lycopersicum (cv. Heinz 1706), control (wild-type/WT) and eight different $500 \quad$ L1L4 gene disruption lines from $\mathrm{M}_{4}$ generation, obtained at Institute of Applied Biosciences (Thessaloniki, Thermi, 57001, Greece) were sown in a plastic greenhouse at the University of Algarve (located in Faro, Portugal), and the resulting seedlings were transplanted to pots. Plants were grown in the greenhouse under normal culture procedures until the end of fruit harvest 
period in June-July 2013. The greenhouse was ventilated when the temperature exceeded $24^{\circ} \mathrm{C}$. For each tomato line and replication, 6 to 10 completely red and firm ripe fruits were harvested randomly from different plants of the same genetic line.

\section{ZFN-based L1L4 mutant lines}

ZFN technology was used to develop tomato lines in which the L1L4 has been disrupted in the coding region (Hilioti, et al. 2016). Different L1L4 disruption lines of $\mathrm{M}_{4}$ generation were selected by genotyping.

\section{RNA extraction and cDNA synthesis}

RNA from leaf tissue (100 mg) was extracted using the NucleoSpin RNA plant kit (MachereyNagel). cDNA synthesis was performed using the PrimeScript first strand cDNA synthesis kit (TaKaRa). To detect DNA changes at target site, cDNA isolated from mutant lines of M4 generation and wild type (control) was used as template in PCR-based analysis.

\section{Detection of ZFN-induced modifications at L1L4 locus}

High Resolution Melting (HRM) analysis on founder plants and selected progenies (M 4 generation) was performed using F1: GCTATCGCAGATCTCCACAACCAACC and R2: CGTTTGGTATGACTTCGTCTTGCTCCTG primers flanking the L1L4 (Solyc05g005350) target site to amplify a $131 \mathrm{bp}$ product in cDNA. HRM analysis was performed in a total volume of $15 \mu \mathrm{L}$ on a Rotor-Gene 6000 real-time 5P HRM PCR Thermocycler (Corbett Research, Sydney, Australia). The reaction mixture contained 20 ng genomic DNA, 1X PCR buffer, 2.5 $\mathrm{mM} \mathrm{MgCl} 2,0.2 \mathrm{mM}$ dNTP, $300 \mathrm{nM}$ forward and reverse primers, $1.5 \mathrm{mM}$ Syto® 9 green fluorescent nucleic acid stain (Life Technologies Corp., Paisley, UK) and 1 U Kapa Taq DNA 
polymerase (Kapa Biosystems, Cape Town, South Africa). The PCR protocol was conducted in a 36-well carousel, using an initial denaturing step of $95^{\circ} \mathrm{C}$ for $3 \mathrm{~min}$ followed by 35 cycles of denaturation at $95{ }^{\circ} \mathrm{C}$ for $20 \mathrm{sec}$, annealing at $60{ }^{\circ} \mathrm{C}$ for $20 \mathrm{sec}$, extension at $72{ }^{\circ} \mathrm{C}$ for $20 \mathrm{sec}$ and final extension at $72{ }^{\circ} \mathrm{C}$ for $10 \mathrm{~min}$. All samples including the wild-type were plotted according to their melting profiles. Shape differences in melting curves relative to wild-type control were indicative of sequence changes within the amplicon analyzed. For sequencing data, primers F4: ATGGATGGTGGTTCAGGAAATG and R2 (as above) were used in PCR reactions with cDNA as template.

\section{Fruit size, color evaluation and fruit quality parameters}

Following fruit maturity, a minimum of 18 ripe tomatoes (3 replication with 6 fruits each one) from each line were evaluated for a series of phenotypic traits related to fruit size: fruit weight, in grams; fruit length was obtained by measuring, in centimeters, from stem to blossom end; fruit width was measured, in the equatorial zone of the fruit, using a caliper.

543 Tomato surface color was determined at 3 points around the fruit using a Chroma meter CR-300 544 series (CE Minolta, Japan) in CIE L* $\mathrm{a}^{*} \mathrm{~b}^{*}$ color space. The $\mathrm{L}^{*}$ value indicates lightness 545 (black=0 and white=100), a* changes from green (negative values) to red (positive values) and $b^{*}$ from blue (negative values) to yellow (positive values). The $a^{*}$ and $b^{*}$ readings were 547 converted to the vectorial coordinates hue angle $(\mathrm{h})$ and chroma $\left(\mathrm{C}^{*}\right)$ using the equations $\mathrm{h}=\operatorname{arc}$ $548 \tan b^{*} / a^{*}$ and $C^{*}=\left(a * 2+b^{*} 2\right) 1 / 2$, respectively (McGuire 1992).

550 Firmness was determined on two opposite sides of each fruit using a Chatillon Force TCD 200 551 and Digital Force Gauge DFIS 50 (Jonh Chatillon \& Sons, Inc., Largo, FL, USA), by measuring 
After quantification of the parameters referred to above, the fruits from each replication were longitudinally cut into quarters and all the seeds were extracted for separate analysis. Three quarters of each fruit were stored at $-80{ }^{\circ} \mathrm{C}$ for later use. The remaining quarter of each fruit in each replication was ground using an UltraTurrax mixer T18 (IKA, Starfen, Germany) and the juice was extracted by squeezing the fruit mixture through cheesecloth. The juice aliquot was collected and frozen at $-80{ }^{\circ} \mathrm{C}$ until use. The remaining juice obtained was used to quantify soluble solids content (SSC) and titratable acidity (TA). SSC was measured in juice using a digital refractometer (Model PR-100, Atago Co., Tokyo, Japan).

564 Titratable acidity was determined by titration of the juice with $0.1 \mathrm{M}$ of $\mathrm{NaOH}$ to the end-point of $565 \mathrm{pH} 8.2$ and the results expressed as percentage of citric acid.

568 described (Navez, et al. 1999), using the following expression: $\mathrm{TI}=[\mathrm{SSC}$ pulp/(20*titratable 569 acid)] + titratable acidity.

\section{Moisture, fiber, protein and ash content}

573 Moisture was determined by desiccation at $105^{\circ} \mathrm{C}$ for about $24 \mathrm{~h}$ till constant weight (Horwitz, et 574 al. 2000). Total dietary fiber (TDF) was evaluated using a commercial kit (Sigma-Aldrich, St. 575 Louis MO, USA). This assay determines the TDF content using a combination of enzymatic and 
gravimetric methods (Horwitz, et al. 2000). Lyophilized tomato samples ( $1 \mathrm{~g})$ were gelatinized with a heat-stable $\alpha$-amylase $\left(\mathrm{pH} 6,100{ }^{\circ} \mathrm{C}, 15 \mathrm{~min}\right.$ ) and then enzymatically digested sequentially with protease $\left(\mathrm{pH} 7.5,60{ }^{\circ} \mathrm{C}, 30 \mathrm{~min}\right)$ and amyloglucosidase $\left(\mathrm{pH} 6,60{ }^{\circ} \mathrm{C}, 30 \mathrm{~min}\right)$. TDF was precipitated with ethanol, and after washing and drying, the residue was weighed. Part of the residue was analyzed for nitrogen content by the Kjeldahl method (Bradstreet 1954). Nitrogen content was multiplied by a conversion factor of 6.25 to calculate protein content. Another part of the residue was used for ash analysis by combustion in a furnace at $550{ }^{\circ} \mathrm{C}$ for 5 hours. TDF values were recorded after subtracting protein and ash contents.

\section{Extraction, quantification of sugars and sweetness index}

Extraction and quantification of sugars (fructose, glucose and sucrose) were based on a method described by (Terry, et al. 2007) and modified as described previously (Magwaza, et al. 2012). Briefly, a $150 \pm 0.5 \mathrm{mg}$ of fruit powder was extracted in $3 \mathrm{~mL} 62.5 \%$ (v/v) aqueous methanol. Following extraction, the concentrations of fructose, glucose and sucrose were determined in an HPLC binary pump system (L-2130, Elite LaChrom series, Hitachi, Japan). Ten $\mu$ L of a diluted sample solution (1:10) was injected into a Purospher Star $\mathrm{NH}_{2}$ (amino) column (4.6 mm diameter $\times 250 \mathrm{~mm}, 5 \mu \mathrm{m}$ particle size; Merck Millipore, Germany) with an amino guard column (LiChroCART 4-4 Merck Millipore, Germany). The thermostatic column compartment temperature was set at $35^{\circ} \mathrm{C}$. The mobile phase used was HPLC-grade water at a flow rate of 1.0 $\mathrm{mL} / \mathrm{min}$ and the presence of carbohydrates was detected on a refractive index detector (RID, L2490, Elite LaChrom series, Hitachi, Japan). Sugars were quantified from a linear standard curve $(0.05-1.25 \mathrm{mg} / \mathrm{mL} ;$ average $\mathrm{R} 2=0.99)$.

\section{Extraction and quantification of non-volatile organic acids}


Non-volatile organic acids (ascorbic, citric and oxalic acid) were extracted and determined using a method described previously (Crespo, et al. 2010) with slight modifications (Magwaza, et al. 602 2013). Briefly, $50 \pm 0.5 \mathrm{mg}$ of freeze dried samples were cold extracted for $5 \mathrm{~min}$ in $3 \mathrm{~mL}$ of 603 HPLC water. The flocculate was filtered through a $0.2 \mathrm{~m}$ syringe filter before HPLC analysis. 604 Ascorbic, citric and oxalic acid concentrations were determined on a HPLC binary pump system 605 equipped with a diode array detector (DAD, L-2455, Elite LaChrom series, Hitachi, Japan) with 606 multiple wavelength detector, degasser and cooled autosampler. The filtered sample extract (20

\section{Antioxidant composition}

\section{Extraction and assay of total phenols (Folin-Ciocalteau)}

The total phenolic content was determined using the Folin-Ciocalteau reagent and gallic acid as standard as described by Slinkard and Singleton (Slinkard and Singleton 1977). Tomato juice $(0.2 \mathrm{~mL})$ or gallic acid concentration was mixed with $0.8 \mathrm{~mL}$ of an aqueous sodium carbonate solution $\left(75 \mathrm{~g} \mathrm{~L}^{-1}\right)$ and were added to $1 \mathrm{~mL}$ of $10 \%(\mathrm{v} / \mathrm{v})$ Folin-Ciocalteau reagent. After $30 \mathrm{~min}$ of reaction at room temperature, the absorbance was measured at $765 \mathrm{~nm}$ in a Shimadzu, UVvisible recording spectrophotometer model UV-160A (Shimadzu Corporation, Kyoto, Japan). 


\section{$\beta$-Carotene and lycopene}

$\beta$-Carotene and lycopene were determined following a procedure previously described (Nagata and Yamashita, I 1992; Pinela, et al. 2012), measuring the absorbance at 453, 505, 645 and 663 $\mathrm{nm}$. Contents were calculated according to the following equations: $\beta$-carotene $(\mathrm{mg} / 100 \mathrm{ml})=$ $0.216 \times \mathrm{A}_{663}-1.220 \times \mathrm{A}_{645}-0.304 \times \mathrm{A}_{505}+0.452 \times \mathrm{A}_{453} ;$ lycopene $(\mathrm{mg} / 100 \mathrm{ml})=-0.0458 \times$ $\mathrm{A}_{663}+0.204 \times \mathrm{A}_{645}-0.304 \times \mathrm{A}_{505}+0.452 \times \mathrm{A}_{453}$, and further expressed in mg per $100 \mathrm{~g}$ fruit. $\mathrm{A}_{663}, \mathrm{~A}_{645}, \mathrm{~A}_{505}$ and $\mathrm{A}_{453}$ are absorbance at $663 \mathrm{~nm}, 645 \mathrm{~nm}, 505 \mathrm{~nm}$ and $453 \mathrm{~nm}$, respectively.

\section{Flavonoid content}

633 Flavonoid content was quantified as described by (Ahn, et al. 2007). Briefly, $0.5 \mathrm{~mL}$ of $2 \%$ $634 \mathrm{AlCl}_{3}$-ethanol solution was added to $0.5 \mathrm{~mL}$ of sample or standard. After $1 \mathrm{~h}$ at room 635 temperature, the absorbance was measured at $420 \mathrm{~nm}$. Quercetin was used as standard for the 636 construction of calibration curve.

\section{Evaluation of antioxidant activity}

639 Oxygen radical absorbance capacity (ORAC)

641 peroxyl radicals. The ORAC method used, with fluorescein (FL) as the fluorescent probe, was 642 that described previously (Ou, et al. 2001). As the ORAC assay is extremely sensitive, the 643 samples must be diluted appropriately before analysis to avoid interference. In each well, $150 \mu \mathrm{L}$ 644 of fluorescein working solution and $25 \mu \mathrm{L}$ sample previously diluted, blank (75 mM phosphate 645 buffer) or standard (Trolox) were placed. The plate was covered with a lid and incubated in the 646 pre-heated $\left(37^{\circ} \mathrm{C}\right)$ Tecan Infinite M200 Microplate Reader for 10 min with a previous shaking 647 of 3 min. The 2, 2-Azobis-2-methyl-propanimidamide dihydrochloride (AAPH) was added to 
648 each well of the plate, except for the control and blank. The final volume of the assay was 200 $649 \mu \mathrm{L}$. The fluorescence was read every minute for $90 \mathrm{~min}$ at excitation of $485 \mathrm{~nm}$ and emission of $650527 \mathrm{~nm}$. The ORAC values are calculated according to a previous work (Huang, et al. 2002). 651 Briefly, the net area under the curve (AUC) of the standards and samples was calculated. The 652 standard curve was obtained by plotting Trolox concentrations against the average net AUC of 653 the two measurements for each concentration. Final ORAC values were calculated using the 654 regression equation between Trolox concentration and the net AUC and were expressed as mmol 655 Trolox/100 g fresh weight.

\section{Trolox equivalent antioxidant activity (TEAC)}

658 The preformed radical monocation of 2, 2-azinobis-(3-ethylbenzo-thiazoline-6-sulfonic acid) 659 (ABTS) was generated according to the modified method of $\mathrm{Re}$ et al. (Re, et al. 1999), as 660 described elsewhere (Antunes, et al. 2010). For the assay, $10 \mu \mathrm{L}$ of the extract was added to 990 $661 \mu \mathrm{L}$ of ABTS radical cation solution. The absorbance was monitored spectrophotometrically at $662735 \mathrm{~nm}$ for $6 \mathrm{~min}$ (Shimadzu spectrophotometer 160-UV). The antioxidant activity of each 663 sample was calculated using the following equation: scavenging effect $\%(\mathrm{IA} \%)=(1-\mathrm{Af} / \mathrm{A} 0) \times$ 664 100, where A0 stands for the absorbance of the control and Af for the absorbance in the presence 665 of the sample. The values were compared with the standard curve constructed with a series of

\section{LC-MC/MS-based metabolic profiling in tomato seeds}

670 Wild-type and L1L4 mutant seeds of the $\mathrm{M}_{4}$ generation were ground in liquid nitrogen and stored at $-80{ }^{\circ} \mathrm{C}$. Mature seed tissue was extracted in $80 \%$ methanol (HPLC grade) and then vortexed 
7

8

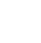
.

for about $20 \mathrm{~s}$. Subsequently, the samples were centrifuged at $11,000 \mathrm{~g}$ for $15 \mathrm{~min}$ at $4{ }^{\circ} \mathrm{C}$ to remove protein pellets. Next, the cleared supernatants containing extracted metabolites were transferred into aliquots for LC-MS/MS analyses. Metabolites were identified by triplicate analysis of single seed extracts.

\section{Statistical analysis}

Analysis of variance (ANOVA) was performed on the data and, when needed, means were compared using Duncan's Multiple Range Test at $\mathrm{P}<0.05$. Pearson correlation was used to test whether two traits varied together for all possible pairwise comparisons. Software utilized for the statistical treatments was SPSS (SPSS Inc., Chicago, USA). Principal component analysis (PCA) and hierarchical cluster analysis (HCA) were performed using the statistical software Chemoface version 1.5 (Nunes, et al. 2012).

\section{Metabolic and gene pathway inference}

The metabolic pathways as well as the gene identities in each pathway have been computationally predicted by PMN (http://pmn.plantcyc.org/) using species-specific pathway databases, selection of the initial and end metabolite and specification of the number of maximum path length.

\section{ACKNOWLEDGMENTS}

693 This work was benefited from the networking activities within the European funded COST ACTION FA1106 Quality Fruit. 


\section{AUTHOR CONTRIBUTION STATEMENT}

Z.H. and. D. A designed, performed and supervised experiments, analyzed data and wrote the article; C.G. and V.D. performed experiments; analyzed data and wrote parts of the article; K. P., A. G., and G. M. performed experiments of the project and edited the article.

\section{CONFLICT OF INTEREST}

The authors declare that they have no conflict of interest.

\section{REFERENCES}

Ahn M-R, Kumazawa S, Usui Y, Nakamura J, Matsuka M, Zhu F, Nakayama T (2007) Antioxidant activity and constituents of propolis collected in various areas of China. Food Chemistry 101:1383-1392

Anthon GE, LeStrange M, Barrett DM (2011) Changes in pH, acids, sugars and other quality parameters during extended vine holding of ripe processing tomatoes. Journal of the Science of Food and Agriculture 91:1175-1181

Antunes MDC, Dandlen S, Cavaco AM, Miguel Ga (2010) Effects of postharvest application of $1-\mathrm{MCP}$ and postcutting dip treatment on the quality and nutritional properties of fresh-cut kiwifruit. Journal of agricultural and food chemistry 58:6173-6181

Antunes MDC, Rodrigues D, Pantazis V, Cavaco AM, Siomos AS, Miguel G (2013) Nutritional quality changes of fresh-cut tomato during shelf life. Food Science and Biotechnology 22:1-8 Arias R, Lee T-C, Logendra L, Janes H (2000) Correlation of lycopene measured by HPLC with the $\mathrm{L}^{*}, \mathrm{a}^{*}, \mathrm{~b}^{*}$ color readings of a hydroponic tomato and the relationship of maturity with color and lycopene content. Journal of agricultural and food chemistry 48:1697-1702 Atanassova B, Stoeva-Popova P, Balacheva E (2007) Cumulating useful traits in processing tomato. Acta Horticulturae 27-36

Barrero LS, Cong B, Wu F, Tanksley SD (2006) Developmental characterization of the fasciated locus and mapping of Arabidopsis candidate genes involved in the control of floral meristem size and carpel number in tomato. Genome 49:991-1006

Beecher GR (1998) Nutrient content of tomatoes and tomato products. Experimental Biology and Medicine 218:98-100

Bhattacharya S, Manna P, Gachhui R, Sil PC (2013) D-saccharic acid 1, 4-lactone protects diabetic rat kidney by ameliorating hyperglycemia-mediated oxidative stress and renal inflammatory cytokines via NF-kB and PKC signaling. Toxicology and applied pharmacology 267:16-29

Bono H, Ogata H, Goto S, Kanehisa M (1998) Reconstruction of amino acid biosynthesis pathways from the complete genome sequence. Genome research 8:203-210 Bradstreet RB (1954) Kjeldahl method for organic nitrogen. Analytical Chemistry 26:185-187 
Breksa AP, Robertson LD, Labate JA, King BA, King DE (2015) Physicochemical and morphological analysis of ten tomato varieties identifies quality traits more readily manipulated through breeding and traditional selection methods. Journal of Food Composition and Analysis 42:16-25

Causse M, Saliba-Colombani V, Lecomte L, Duffe P, Rousselle P, Buret M (2002) QTL analysis of fruit quality in fresh market tomato: a few chromosome regions control the variation of sensory and instrumental traits. Journal of experimental botany 53:2089-2098

Chang C-H, Lin H-Y, Chang C-Y, Liu Y-C (2006) Comparisons on the antioxidant properties of fresh, freeze-dried and hot-air-dried tomatoes. Journal of Food Engineering 77:478-485

Chassy AW, Bui L, Renaud EN, Van Horn M, Mitchell AE (2006) Three-year comparison of the content of antioxidant microconstituents and several quality characteristics in organic and conventionally managed tomatoes and bell peppers. Journal of agricultural and food chemistry 54:8244-8252

Chen D, Chen MS, Cui QC, Yang H, Dou QP (2006) Structure-proteasome-inhibitory activity relationships of dietary flavonoids in human cancer cells. Frontiers in bioscience: a journal and virtual library 12:1935-1945

Choi SH, Kim D-S, Kozukue N, Kim H-J, Nishitani Y, Mizuno M, Levin CE, Friedman M (2014) Protein, free amino acid, phenolic, $\beta$-carotene, and lycopene content, and antioxidative and cancer cell inhibitory effects of 12 greenhouse-grown commercial cherry tomato varieties. Journal of Food Composition and Analysis 34:115-127

Crespo P, Bordonaba JG, Terry LA, Carlen C (2010) Characterisation of major taste and healthrelated compounds of four strawberry genotypes grown at different Swiss production sites. Food Chemistry 122:16-24

Dai N, Kandel-Kfir M, Petreikov M, Hanael R, Levin I, Ricard Brn, Rothan C, Schaffer AA, Granot D (2002) The tomato hexokinase LeHXK1 cloning, mapping, expression pattern and phylogenetic relationships. Plant Science 163:581-590

Davies JN (1966) Changes in the non-volatile organic acids of tomato fruit during ripening. Journal of the Science of Food and Agriculture 17:396-400

Dumas Y, Dadomo M, Di Lucca G, Grolier P (2003) Effects of environmental factors and agricultural techniques on antioxidantcontent of tomatoes. Journal of the Science of Food and Agriculture 83:369-382

Dwivedi C, Heck WJ, Downie AA, Larroya S, Webb TE (1990) Effect of calcium glucarate on $\beta$-glucuronidase activity and glucarate content of certain vegetables and fruits. Biochemical medicine and metabolic biology 43:83-92

Etienne A, Génard M, Lobit P, Mbeguié-A-Mbéguié D, Bugaud C (2013) What controls fleshy fruit acidity? A review of malate and citrate accumulation in fruit cells. Journal of Experimental Botany 64:1451-1469

Ferreira MMM (2001) Índice de nitrogênio para o diagnóstico do estado nutricional do tomateiro em presença e ausência de adubação orgânica. Universidade Federal de Viçosa, Viçosa, Brazil Fulton TM, Beck-Bunn T, Emmatty D, Eshed Y, Lopez J, Petiard V, Uhlig J, Zamir D, Tanksley SD (1997) QTL analysis of an advanced backcross of Lycopersicon peruvianum to the cultivated tomato and comparisons with QTLs found in other wild species. Theoretical and Applied Genetics 95:881-894

Fulton TM, Grandillo S, Beck-Bunn T, Fridman E, Frampton A, Lopez J, Petiard V, Uhlig J, Zamir D, Tanksley SD (2000) Advanced backcross QTL analysis of a Lycopersicon esculentum - Lycopersicon parviflorum cross. Theoretical and Applied Genetics 100:1025-1042 
George B, Kaur C, Khurdiya DS, Kapoor HC (2004) Antioxidants in tomato (Lycopersium esculentum) as a function of genotype. Food chemistry 84:45-51

Giannelos PN, Sxizas S, Lois E, Zannikos F, Anastopoulos G (2005) Physical, chemical and fuel related properties of tomato seed oil for evaluating its direct use in diesel engines. Industrial crops and products 22:193-199

Giovannoni JJ (2004) Genetic regulation of fruit development and ripening. The Plant Cell 16:S170-S180

Giovannoni JJ (2007) Fruit ripening mutants yield insights into ripening control. Current opinion in plant biology 10:283-289

Gómez-Romero M, Segura-Carretero A, Fernández-Gutiérrez A (2010) Metabolite profiling and quantification of phenolic compounds in methanol extracts of tomato fruit. Phytochemistry $71: 1848-1864$

Grandillo S, Ku H-M, Tanksley SD (1996) Characterization offs8. 1, a major QTL influencing fruit shape in tomato. Molecular Breeding 2:251-260

Hamid AA, Aiyelaagbe OO, Usman LA, Ameen OM, Lawal A (2010) Antioxidants: Its medicinal and pharmacological applications. Afr J Pure Appl Chem 4:142-151

Hilhorst HWM, Groot SPC, Bino RJ (1998) The tomato seed as a model system to study seed development and germination. Acta Botanica Neerlandica 47:169-183

Hilhorst HWM, Groot SPC, Bino RJ (1998) The tomato seed as a model system to study seed germination. Acta Botanica Neerlandica 47:169-183

Hilioti Z, Ganopoulos I, Ajith S, Bossis I, Tsaftaris A (2016) A novel arrangement of zinc finger nuclease system for in vivo targeted genome engineering: the tomato LEC1-LIKE4 gene case. Plant cell reports 35:2241-2255

Hilioti Z, Ganopoulos I, Bossis I, Tsaftaris A (2014) LEC1-LIKE paralog transcription factor: how to survive extinction and fit in NF-Y protein complex. Gene 543:220-233

Horwitz W, International A, Association of Official Analytical C, Cunniff P (2000) Official Methods of Analysis of AOAC International: Food composition ; additives ; natural contaminants. AOAC International

Hougee S, Sanders A, Faber J, Graus YMF, van den Berg WB, Garssen J, Smit HF, Hoijer MA (2005) Decreased pro-inflammatory cytokine production by LPS-stimulated PBMC upon in vitro incubation with the flavonoids apigenin, luteolin or chrysin, due to selective elimination of monocytes/macrophages. Biochemical Pharmacology 69:241-248

Huang D, Ou B, Hampsch-Woodill M, Flanagan JA, Prior RL (2002) High-throughput assay of oxygen radical absorbance capacity (ORAC) using a multichannel liquid handling system coupled with a microplate fluorescence reader in 96-well format. Journal of agricultural and food chemistry 50:4437-4444

Ilahy R, Hdider C, Lenucci MS, Tlili I, Dalessandro G (2011) Antioxidant activity and bioactive compound changes during fruit ripening of high-lycopene tomato cultivars. Journal of Food Composition and Analysis 24:588-595

Ilahy R, Hdider C, Lenucci MS, Tlili I, Dalessandro G (2011) Phytochemical composition and antioxidant activity of high-lycopene tomato (Solanum lycopersicum L.) cultivars grown in Southern Italy. Scientia Horticulturae 127:255-261

Islam MS, Matsui T, Yoshida Y (1996) Effect of carbon dioxide enrichment on physicochemical and enzymatic changes in tomato fruits at various stages of maturity. Scientia Horticulturae 65:137-149 
Juroszek P, Lumpkin HM, Yang R-Y, Ledesma DR, Ma C-H (2009) Fruit quality and bioactive compounds with antioxidant activity of tomatoes grown on-farm: comparison of organic and conventional management systems. Journal of agricultural and food chemistry 57:1188-1194 Kagaya Y, Toyoshima R, Okuda R, Usui H, Yamamoto A, Hattori T (2005) LEAFY COTYLEDON1 controls seed storage protein genes through its regulation of FUSCA3 and ABSCISIC ACID INSENSITIVE3. Plant and cell physiology 46:399-406

Kalogeropoulos N, Chiou A, Pyriochou V, Peristeraki A, Karathanos VT (2012) Bioactive phytochemicals in industrial tomatoes and their processing byproducts. Food Science and Technology 49:213-216

Kandel-Kfir M, Damari-Weissler H, German MA, Gidoni D, Mett A, Belausov E, Petreikov M, Adir N, Granot D (2006) Two newly identified membrane-associated and plastidic tomato HXKs: characteristics, predicted structure and intracellular localization. Planta 224:1341-1352

Ku HM, Doganlar S, Chen KY, Tanksley SD (1999) The genetic basis of pear-shaped tomato fruit. Theoretical and Applied Genetics 99:844-850

Ku HM, Grandillo S, Tanksley SD (2000) fs8. 1, a major QTL, sets the pattern of tomato carpel shape well before anthesis. Theoretical and Applied Genetics 101:873-878

Kwong RW, Bui AQ, Lee H, Kwong LW, Fischer RL, Goldberg RB, Harada JJ (2003) LEAFY COTYLEDON1-LIKE defines a class of regulators essential for embryo development. The Plant Cell 15:5-18

Le Marchand Lc (2002) Cancer preventive effects of flavonoids-a review. Biomedicine \& pharmacotherapy 56:296-301

Li M, Wei F, Tawfall A, Tang M, Saettele A, Wang X (2015) Overexpression of patatin-related phospholipase AIII $\delta$ altered plant growth and increased seed oil content in camelina. Plant biotechnology journal 13:766-778

Li X-Y, Mantovani R, van Huijsduijnen RH, Andre I, Benoist C, Mathis D (1992) Evolutionary variation of the CCAAT-binding transcription factor NF-Y. Nucleic acids research 20:1087-1091 Lippman Z, Tanksley SD (2001) Dissecting the genetic pathway to extreme fruit size in tomato using a cross between the small-fruited wild species Lycopersicon pimpinellifolium and $\mathrm{L}$. esculentum var. Giant Heirloom. Genetics 158:413-422

Liu J, Van Eck J, Cong B, Tanksley SD (2002) A new class of regulatory genes underlying the cause of pear-shaped tomato fruit. Proceedings of the National Academy of Sciences 99:1330213306

López MG, Zanor MI, Pratta GR, Stegmayer G, Boggio SB, Conte M, Bermúdez L, Leskow CC, Rodríguez GR, Picardi LA (2015) Metabolic analyses of interspecific tomato recombinant inbred lines for fruit quality improvement. Metabolomics 1-16

Lotan T, Ohto M-a, Yee KM, West MAL, Lo R, Kwong RW, Yamagishi K, Fischer RL, Goldberg RB, Harada JJ (1998) Arabidopsis LEAFY COTYLEDON1 is sufficient to induce embryo development in vegetative cells. Cell 93:1195-1205

Luthria DL, Mukhopadhyay S, Krizek DT (2006) Content of total phenolics and phenolic acids in tomato (Lycopersicon esculentum Mill.) fruits as influenced by cultivar and solar UV radiation. Journal of Food Composition and Analysis 19:771-777

Müller L, Fröhlich K, Böhm V (2011) Comparative antioxidant activities of carotenoids measured by ferric reducing antioxidant power (FRAP), ABTS bleaching assay ( $\alpha$ TEAC), DPPH assay and peroxyl radical scavenging assay. Food Chemistry 129:139-148 
Magwaza LS, Opara UL, Terry LA, Landahl S, Cronje PJ, Nieuwoudt H, Mouazen AM, Saeys W, Nicolai BM (2012) Prediction of 'Nules Clementine' mandarin susceptibility to rind breakdown disorder using Vis/NIR spectroscopy. Postharvest Biology and Technology 74:1-10 Magwaza LS, Opara UL, Terry LA, Landahl S, Cronje PJR, Nieuwoudt HH, Hanssens A, Saeys W, Nicolai BM (2013) Evaluation of Fourier transform-NIR spectroscopy for integrated external and internal quality assessment of Valencia oranges. Journal of Food Composition and Analysis 31:144-154

Mahakun N, Leeper PW, Burns EE (1979) Acidic constituents of various tomato fruit types. Journal of Food Science 44:1241-1244

Maity SN, de Crombrugghe B (1992) Biochemical analysis of the B subunit of the heteromeric CCAAT-binding factor. A DNA-binding domain and a subunit interaction domain are specified by two separate segments. Journal of Biological Chemistry 267:8286-8292

Mantovani R (1999) The molecular biology of the CCAAT-binding factor NF-Y. Gene 239:1527

McGuire RG (1992) Reporting of objective color measurements. HortScience 27:1254-1255

McNabb DS, Xing Y, Guarente L (1995) Cloning of yeast HAP5: a novel subunit of a heterotrimeric complex required for CCAAT binding. Genes \& Development 9:47-58

Méndez I I, Vera G AM, Chávez S J, Carrillo R J (2011) Quality of fruits in Mexican tomato (Lycopersicon esculentum Mill.) landraces. VITAE-Revista de la Facultad de Química Farmacéutica 18:26-32

Menu T, Rothan C, Dai N, Petreikov M, Etienne C, Destrac-Irvine A, Schaffer A, Granot D, Ricard Brn (2001) Cloning and characterization of a cDNA encoding hexokinase from tomato. Plant Science 160:209-218

Miean KH, Mohamed S (2001) Flavonoid (myricetin, quercetin, kaempferol, luteolin, and apigenin) content of edible tropical plants. Journal of agricultural and food chemistry 49:31063112

Mounet F, Lemaire-Chamley M, Maucourt Ml, Cabasson Cc, Giraudel J-L, Deborde C, Lessire R, Gallusci P, Bertrand A, Gaudillère M (2007) Quantitative metabolic profiles of tomato flesh and seeds during fruit development: complementary analysis with ANN and PCA. Metabolomics 3:273-288

Mu J, Tan H, Zheng Q, Fu F, Liang Y, Zhang J, Yang X, Wang T, Chong K, Wang X-J (2008) LEAFY COTYLEDON1 is a key regulator of fatty acid biosynthesis in Arabidopsis. Plant physiology 148:1042-1054

Nagata M, Yamashita, I (1992) Simple method for simultaneous determination of chlorophyll and carotenoids in tomato fruit. Nippon Shokuhin Kogyo Gakkaish 39:925-928

Navez B, Letard M, Grasselly D, Jost M (1999) Tomatoes: criteria for quality. Infos CTIFL Nunes CA, Freitas MP, Pinheiro ACM, Bastos SC (2012) Chemoface: a novel free user-friendly interface for chemometrics. Journal of the Brazilian Chemical Society 23:2003-2010

Obied HK, Bedgood DR, Prenzler PD, Robards K (2007) Chemical screening of olive biophenol extracts by hyphenated liquid chromatography. Analytica Chimica Acta 603:176-189

Odriozola-Serrano I, Soliva-Fortuny R, Martín-Belloso O (2008) Effect of minimal processing on bioactive compounds and color attributes of fresh-cut tomatoes. LWT-Food Science and Technology 41:217-226

Osvald Je, Petrovic N, Demsar J (2001) Sugar and organic acid content of tomato fruits (Lycopersicon lycopersicum Mill.) grown on aeroponics at different plant density. Acta Alimentaria 30:53-61 
Ou B, Hampsch-Woodill M, Prior RL (2001) Development and validation of an improved oxygen radical absorbance capacity assay using fluorescein as the fluorescent probe. Journal of agricultural and food chemistry 49:4619-4626

Paran I, van der Knaap E (2007) Genetic and molecular regulation of fruit and plant domestication traits in tomato and pepper. Journal of Experimental Botany 58:3841-3852

Persia ME, Parsons CM, Schang M, Azcona J (2003) Nutritional evaluation of dried tomato seeds. Poultry science $82: 141-146$

Pinela J, Barros L, Carvalho AM, Ferreira ICFR (2012) Nutritional composition and antioxidant activity of four tomato (Lycopersicon esculentum L.) farmerâ $€^{\mathrm{TM}_{\mathrm{v}}}$ arieties in Northeastern Portugal homegardens. Food and Chemical Toxicology 50:829-834

Powell ALT, Nguyen CV, Hill T, Cheng KL, Figueroa-Balderas R, Aktas H, Ashrafi H, Pons C, Fernández-Muñoz R, Vicente A (2012) Uniform ripening encodes a Golden 2-like transcription factor regulating tomato fruit chloroplast development. Science 336:1711-1715

Re R, Pellegrini N, Proteggente A, Pannala A, Yang M, Rice-Evans C (1999) Antioxidant activity applying an improved ABTS radical cation decolorization assay. Free radical biology and medicine 26:1231-1237

Rezai-Zadeh K, Ehrhart J, Bai Y, Sanberg PR, Bickford P, Tan J, Shytle RD (2008) Apigenin and luteolin modulate microglial activation via inhibition of STAT1-induced CD40 expression. Journal of Neuroinflammation 5:41

Rigano MM, De Guzman G, Walmsley AM, Frusciante L, Barone A (2013) Production of pharmaceutical proteins in solanaceae food crops. International journal of molecular sciences 14:2753-2773

Rodríguez GR, Muños S, Anderson C, Sim S-C, Michel A, Causse M, Gardener BBM, Francis D, van der Knaap E (2011) Distribution of SUN, OVATE, LC, and FAS in the tomato germplasm and the relationship to fruit shape diversity. Plant Physiology 156:275-285

Rosati C, Aquilani R, Dharmapuri S, Pallara P, Marusic C, Tavazza R, Bouvier F, Camara B, Giuliano G (2000) Metabolic engineering of beta-carotene and lycopene content in tomato fruit. The Plant Journal 24:413-420

Serrano-Megías M, López-Nicolás JM (2006) Application of agglomerative hierarchical clustering to identify consumer tomato preferences: influence of physicochemical and sensory characteristics on consumer response. Journal of the Science of Food and Agriculture 86:493499

Simandle PA, Brogdon JL, Mobley EO, Davis EW (1966) Quality of six tomato cultivars as affected by some compositional factors. Proc Amer Hort Sci 81:532-538

Sinha S, Maity SN, Lu J, de Crombrugghe B (1995) Recombinant rat CBF-C, the third subunit of $\mathrm{CBF} / \mathrm{NFY}$, allows formation of a protein-DNA complex with CBF-A and CBF-B and with yeast HAP2 and HAP3. Proceedings of the National Academy of Sciences 92:1624-1628

Slinkard K, Singleton VL (1977) Total phenol analysis: automation and comparison with manual methods. American Journal of Enology and Viticulture 28:49-55

Stevens MA (1986) Inheritance of tomato fruit quality components. Plant Breeding Reviews, volume 4 273-311

Stevens MA, Rick CM (1986) Genetics and breeding. In: The tomato crop. Springer, pp 35-109 Suárez MH, Rodríguez EMR, Romero CD (2008) Chemical composition of tomato (Lycopersicon esculentum) from Tenerife, the Canary Islands. Food Chemistry 106:1046-1056 Suárez MH, Rodríguez ER, Romero CD (2008) Analysis of organic acid content in cultivars of tomato harvested in Tenerife. European Food Research and Technology 226:423-435 
Swamy BP, Sarla N (2008) Yield-enhancing quantitative trait loci (QTLs) from wild species. Biotechnology advances 26:106-120

Terry LA, Chope GA, Bordonaba JG (2007) Effect of water deficit irrigation and inoculation with Botrytis cinerea on strawberry (Fragaria $\mathrm{x}$ ananassa) fruit quality. Journal of agricultural and food chemistry 55:10812-10819

Tomato Genome C (2012) The tomato genome sequence provides insights into fleshy fruit evolution. Nature 485:635-641

Toor RK, Savage GP (2005) Antioxidant activity in different fractions of tomatoes. Food Research International 38:487-494

Vallverdú-Queralt A, Jáuregui O, Di Lecce G, Andrés-Lacueva C, Lamuela-Raventós RM (2011) Screening of the polyphenol content of tomato-based products through accurate-mass spectrometry (HPLC-ESI-QTOF). Food chemistry 129:877-883

Van der Knaap E, Lippman ZB, Tanksley SD (2002) Extremely elongated tomato fruit controlled by four quantitative trait loci with epistatic interactions. Theoretical and Applied Genetics 104:241-247

Van der Knaap E, Sanyal A, Jackson SA, Tanksley SD (2004) High-resolution fine mapping and fluorescence in situ hybridization analysis of sun, a locus controlling tomato fruit shape, reveals a region of the tomato genome prone to DNA rearrangements. Genetics 168:2127-2140

Van der Knaap E, Tanksley SD (2001) Identification and characterization of a novel locus controlling early fruit development in tomato. Theoretical and Applied Genetics 103:353-358

Voelker T, Kinney AJ (2001) Variations in the biosynthesis of seed-storage lipids. Annual review of plant biology 52:335-361

Walaszek Z (1990) Potential use of D-glucaric acid derivatives in cancer prevention. Cancer letters $54: 1-8$

Walaszek Z, Szemraj J, Hanausek M, Adams AK, Sherman U (1996) D-glucaric acid content of various fruits and vegetables and cholesterol-lowering effects of dietary D-glucarate in the rat. Nutrition Research 16:673-681

Wheeler GL, Jones MA, Smirnoff N (1998) The biosynthetic pathway of vitamin C in higher plants. Nature 393:365-369

Wood M (1992) Solid future for tomatoes; breeders are producing fruit with less water, thicker juice. Agricultural Research 40:4-6

Xiao H, Jiang N, Schaffner E, Stockinger EJ, van der Knaap E (2008) A retrotransposonmediated gene duplication underlies morphological variation of tomato fruit. Science 319:15271530

Yao LH, Jiang YM, Shi J, Tomas-Barberan FA, Datta N, Singanusong R, Chen SS (2004) Flavonoids in food and their health benefits. Human Nutrition 59:113-122

Yelle S, Chetelat RT, Dorais M, DeVerna JW, Bennett AB (1991) Sink metabolism in tomato fruit IV. Genetic and biochemical analysis of sucrose accumulation. Plant Physiology 95:10261035

Zeikus JG, Jain MK, Elankovan P (1999) Biotechnology of succinic acid production and markets for derived industrial products. Applied Microbiology and Biotechnology 51:545-552

\section{Table legends}

Table 1. Quality parameters of tomato fruit from wild-type and L1LA disruption lines. 
Table 2. Composition of fruit from wild-type tomato and L1LA disruption lines.

\section{Figure legends}

Figure 1. Selection of lines carrying different single gene mutations

(A) Mutation scanning at L1L4 locus using HRM analysis. A 131-bp fragment (exon 1 end exon 2 beginning) was amplified from each cDNA sample of 8 ZFN-L1L4 tomato lines of $\mathrm{M}_{4}$ generation and a wild-type background. Shown are the normalized temperature HRM curves (WT: red, Line 2: magenta, Line 3: orange, Line 4: beige, Line 5: olive, Line 6: pink, Line 7: blue, Line 8: cyan, Line 9: green). The eight different genotypes of L1L4 gene at the specified region can be seen as curves with shape differences. (B) Genotypes of the L1LA disruption lines. Target site sequences of wild type (WT) and mutant lines (2-9) are aligned. ZFN binding sites are shown in bold letters. A deletion is depicted with dash, an insertion with parenthesis and nucleotide change with red color.

\section{Figure 2. Tomato fruit phenotyping}

Tomato fruit phenotypes from wild-type and $\mathrm{M}_{4} \mathrm{ZFN}-L 1 L 4$ lines.

Figure 3. Principal component analysis of fruit quality parameters 
(A) Scores and loading plot for PC1, PC2 and PC3 for wild-type tomato fruit and 8 L1L4 gene disruption lines. The percentage of total variance explained from each principal component is shown in parentheses. WT=wild-type; $2=$ line $2 ; 3=$ line $3 ; 4=$ line $4 ; 5=$ line; $6=$ line $6 ; 7=$ line 7 ; 8=line 8; 9=line 9. $a=a^{*}$ value; $b=b^{*}$ value; $C^{*}=$ chroma; $L^{*}=$ lightness; $h=$ hue angle; $f d=$ fruit diameter; fl=fruit length; $\mathrm{fw}=$ fruit weight; fm=firmness, TA=titratable acidity; TI=taste index; mo=moisture; pr=protein; fib=fiber; fru=fructose; glu=glucose; fla=flavonoids; ly=lycopene; $\mathrm{bc}=\beta$-carotene; $\mathrm{tp}=$ total phenols content; asc=ascorbic acid; $\mathrm{cit}=\mathrm{citric}$ acid; oxa=oxalic acid; qui=quinic acid; shi=shikimic acid; suc=succinic acid; TE=trolox equivalent antioxidant activity; $\mathrm{OR}=$ oxygen radical absorbance capacity. (B) Dendogram of wild-type tomato fruit and 8 LILA gene disruption lines based on the measured quality and physicochemical variables.

\section{Figure 4. Seed metabolic profiling}

Metabolic profiles in tomato mature seeds from L1L4 disruption lines and wild-type based on LC-MS/MS data. Relative amounts of metabolites in mature seeds from different mutant lines and wild-type background are expressed as \% of the highest amount, which was set as '100'. Results are the means $\pm \mathrm{SD}$.

\section{Figure 5. In silico reconstruction of putative biosynthetic pathways}

Inference of putative metabolic pathways affected by L1L4 coding sequence disruption in lycopene, ascorbate and citrate biosynthesis. The predicted identities of genes encoding key enzymes in the metabolic pathways are shown. Key metabolites in each pathway are shown with squares and end products with circles. Significantly affected metabolites are shown with thick border. 


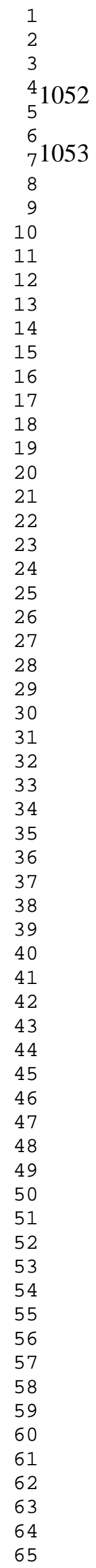

Gago et al. - 39 
Table 1. Quality parameters of tomato fruit from wild-type and LILA gene disruption lines.

\begin{tabular}{|c|c|c|c|c|c|c|c|c|c|c|c|}
\hline \multicolumn{12}{|c|}{ Fruit quality parameters } \\
\hline lines & $\begin{array}{l}\text { Diameter } \\
\qquad(\mathrm{mm})\end{array}$ & $\begin{array}{l}\text { Length } \\
(\mathrm{mm})\end{array}$ & $\begin{array}{l}\text { Weight } \\
\text { (g) }\end{array}$ & Lightness & $a^{*}$ & $b^{*}$ & $a^{*} / b^{*}$ & $\begin{array}{c}\text { Firmness } \\
\text { (N) }\end{array}$ & $\begin{array}{c}\text { Soluble } \\
\text { solid } \\
\text { content (\%) }\end{array}$ & $\begin{array}{l}\text { Titratable } \\
\text { acidity }\end{array}$ & Taste index \\
\hline WT & $34.32 \pm 0.44 a$ & $51.35 \pm 0.4 a$ & $32.66 \pm 1.52 \mathrm{ab}$ & $46.08 \pm 2.48 a$ & $22.03 \pm 2.98 a$ & $19.65 \pm 2.57 \mathrm{abc}$ & $1.12 \pm 0.02 \mathrm{ab}$ & $5.37 \pm 0.56 a$ & $3.6 \pm 0.17 d$ & $0.68 \pm 0.04 a$ & $0.95 \pm 0.03 a b c$ \\
\hline 2 & $34.06 \pm 1.38 a$ & $53.17 \pm 1.08 a$ & $35.77 \pm 5.25 \mathrm{ab}$ & $44.56 \pm 1.92 a$ & $22.57 \pm 1.68 a$ & $22.33 \pm 3.09 a b$ & $1.04 \pm 0.10 \mathrm{ab}$ & $4.46 \pm 0.36 a$ & $3.85 \pm 0.06 \mathrm{~cd}$ & $0.65 \pm 0.03 a b$ & $0.95 \pm 0.01 \mathrm{abc}$ \\
\hline 3 & $32.7 \pm 0.38 a$ & $51.55 \pm 1.00 a$ & $29.35 \pm 0.55 b$ & $46.13 \pm 2.66 a$ & $21.67 \pm 1.67 a$ & $24.76 \pm 1.88 a$ & $0.94 \pm 0.02 b$ & $4.92 \pm 0.9 a$ & $3.9 \pm 0.4 \mathrm{~cd}$ & $0.49 \pm 0.01 d$ & $0.89 \pm 0.02 c$ \\
\hline 4 & $35.79 \pm 0.29 a$ & $56.31 \pm 1.23 a$ & $40.51 \pm 1.86 a$ & $42.15 \pm 1.69 a$ & $22.17 \pm 2.07 a$ & $20.35 \pm 1.83 a b c$ & $1.09 \pm 0.00 \mathrm{ab}$ & $4.84 \pm 0.34 a$ & $4.55 \pm 0.1 \mathrm{ab}$ & $0.56 \pm 0.01 \mathrm{bcd}$ & $0.97 \pm 0.01 \mathrm{ab}$ \\
\hline 5 & $34.34 \pm 1.6 a$ & $55.18 \pm 3.29 a$ & $37.01 \pm 5.51 \mathrm{ab}$ & $47.73 \pm 0.19 a$ & $17.37 \pm 0.11 a$ & $14.77 \pm 0.99 c$ & $1.19 \pm 0.09 a$ & $5.21 \pm 0.36 a$ & $3.93 \pm 0.03 \mathrm{~cd}$ & $0.56 \pm 0.03 \mathrm{~cd}$ & $0.91 \pm 0.01 b c$ \\
\hline 6 & $36.02 \pm 1.11 a$ & $53.57 \pm 1.53 a$ & $38.18 \pm 2.9 a b$ & $45.82 \pm 1.77 a$ & $19.48 \pm 1.97 a$ & $16.24 \pm 2.21 b c$ & $1.21 \pm 0.04 a$ & $5.28 \pm 0.84 a$ & $4.2 \pm 0.1 b c$ & $0.62 \pm 0.04 a b c$ & $0.96 \pm 0.02 \mathrm{ab}$ \\
\hline 7 & $36.69 \pm 0.35 a$ & $52.11 \pm 1.48 a$ & $38.61 \pm 1.02 \mathrm{ab}$ & $43.25 \pm 1.87 a$ & $19.57 \pm 1.20 a$ & $17.35 \pm 2.34 b c$ & $1.17 \pm 0.15 a$ & $4.65 \pm 0.35 a$ & $4.58 \pm 0.2 \mathrm{ab}$ & $0.65 \pm 0.01 \mathrm{ab}$ & $1.00 \pm 0.00 a$ \\
\hline 8 & $35.6 \pm 2.57 a$ & $53.73 \pm 1.62 a$ & $31.77 \pm 2.4 a b$ & $44.42 \pm 2.02 a$ & $22.28 \pm 2.55 a$ & $21.01 \pm 2.13 a b c$ & $1.06 \pm 0.07 a b$ & $5.4 \pm 0.74 a$ & $3.81 \pm 0.51 \mathrm{~cd}$ & $0.55 \pm 0.04 \mathrm{~cd}$ & $0.90 \pm 0.04 c$ \\
\hline 9 & $35.66 \pm 1.08 a$ & $55.12 \pm 2.01 a$ & $38.98 \pm 3.44 a b$ & $44.09 \pm 1.47 a$ & $21.72 \pm 1.51 a$ & $17.65 \pm 2.13 \mathrm{abc}$ & $1.25 \pm 0.08 a$ & $4.55 \pm 0.4 a$ & $4.68 \pm 0.46 a$ & $0.55 \pm 0.02 \mathrm{~cd}$ & $0.98 \pm 0.02 \mathrm{ab}$ \\
\hline
\end{tabular}


Table 2. Composition of fruit from wild-type (WT) tomato and L1L4 gene disruption lines.

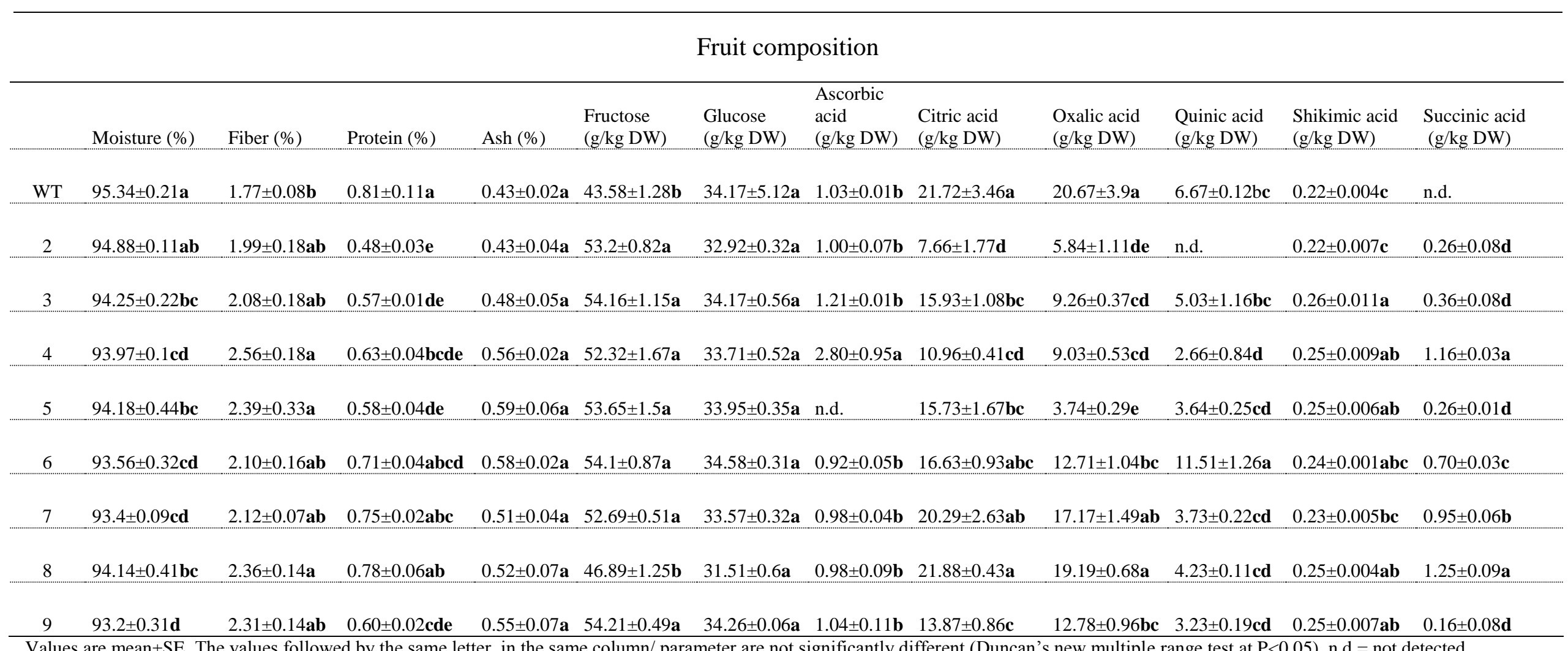

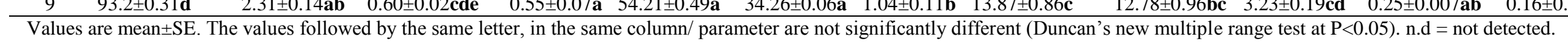


Table 3. Antioxidant composition and antioxidant activity from wild-type (WT) tomato fruit, and from 8 more L1L4 gene disruption lines.

Antioxidant composition and activity

\begin{tabular}{cllllll}
\hline & $\begin{array}{l}\text { Total phenols } \\
\text { (mg gallic } \\
\text { acid/100g FW) }\end{array}$ & $\begin{array}{l}\text { Flavonoids } \\
(\mathrm{g} \text { quercetin/ } \\
100 \mathrm{~g} \mathrm{FW})\end{array}$ & $\begin{array}{l}\text { Lycopene } \\
(\mathrm{mg} /\end{array}$ & $\begin{array}{l}\beta \text {-carotene } \\
(\mathrm{mg} /\end{array}$ & $\begin{array}{l}\text { TEAC } \\
(\mu \mathrm{gmol})\end{array}$ & $\begin{array}{l}\text { ORAC } / 100 \mathrm{~g} \\
(\mu \mathrm{mol} \text { TE} / 100 \mathrm{~g}\end{array}$ \\
$\mathrm{FT}$ & $19.51 \pm 0.47 \mathbf{c}$ & $0.54 \pm 0.12 \mathbf{a}$ & $6.28 \pm 0.72 \mathbf{a b c}$ & $0.74 \pm 0.1 \mathbf{b}$ & $37.75 \pm 3.61 \mathbf{d}$ & $2.2 \pm 0.003 \mathbf{c}$ \\
\hline 2 & $23.18 \pm 0.89 \mathbf{b}$ & $0.5 \pm 0.1 \mathbf{a}$ & $5.98 \pm 1.02 \mathbf{a b c}$ & $0.59 \pm 0.07 \mathbf{b}$ & $53.56 \pm 3.15 \mathbf{a b c}$ & $2.22 \pm 0.024 \mathbf{b c}$ \\
\hline 3 & $25.16 \pm 0.66 \mathbf{b}$ & $0.59 \pm 0.13 \mathbf{a}$ & $5.83 \pm 0.47 \mathbf{b c}$ & $0.71 \pm 0.07 \mathbf{b}$ & $56.66 \pm 1.55 \mathbf{a b}$ & $2.27 \pm 0.012 \mathbf{a b}$ \\
\hline 4 & $23.62 \pm 0.93 \mathbf{b}$ & $0.57 \pm 0.02 \mathbf{a}$ & $5.66 \pm 0.31 \mathbf{b c}$ & $0.44 \pm 0.09 \mathbf{b}$ & $45.01 \pm 1.68 \mathbf{c d}$ & $2.24 \pm 0.025 \mathbf{b c}$ \\
\hline 5 & $24.31 \pm 1.22 \mathbf{b}$ & $0.58 \pm 0.03 \mathbf{a}$ & $7.23 \pm 0.09 \mathbf{a b}$ & $0.65 \pm 0.05 \mathbf{b}$ & $50.97 \pm 3.22 \mathbf{a b c}$ & $2.28 \pm 0.01 \mathbf{a b}$ \\
\hline 6 & $29.31 \pm 0.56 \mathbf{a}$ & $0.64 \pm 0.03 \mathbf{a}$ & $7.51 \pm 0.08 \mathbf{a}$ & $2.66 \pm 0.19 \mathbf{a}$ & $42.24 \pm 5.11 \mathbf{c d}$ & $2.33 \pm 0.04 \mathbf{a}$ \\
\hline 7 & $23.34 \pm 1.14 \mathbf{b}$ & $0.68 \pm 0.05 \mathbf{a}$ & $7.5 \pm 0.08 \mathbf{a}$ & $2.32 \pm 0.43 \mathbf{a}$ & $60.37 \pm 1.21 \mathbf{a}$ & $2.26 \pm 0.002 \mathbf{b c}$ \\
\hline 8 & $22.64 \pm 1.11 \mathbf{b}$ & $0.74 \pm 0.1 \mathbf{a}$ & $5.1 \pm 0.37 \mathbf{c}$ & $0.57 \pm 0.04 \mathbf{b}$ & $45.86 \pm 4.26 \mathbf{b c d}$ & $2.23 \pm 0.012 \mathbf{b c}$ \\
\hline 9 & $29.03 \pm 0.4 \mathbf{a}$ & $0.54 \pm 0.04 \mathbf{a}$ & $7.12 \pm 0.28 \mathbf{a b}$ & $2.66 \pm 0.25 \mathbf{a}$ & $48.91 \pm 4.79 \mathbf{b c d}$ & $2.27 \pm 0.016 \mathbf{a b}$ \\
\hline
\end{tabular}

Values are mean \pm SE. The values followed by the same letter, in the same column/ parameter are not significantly different (Duncan's new multiple range test at $\mathrm{P}<0.05$ ) 
A

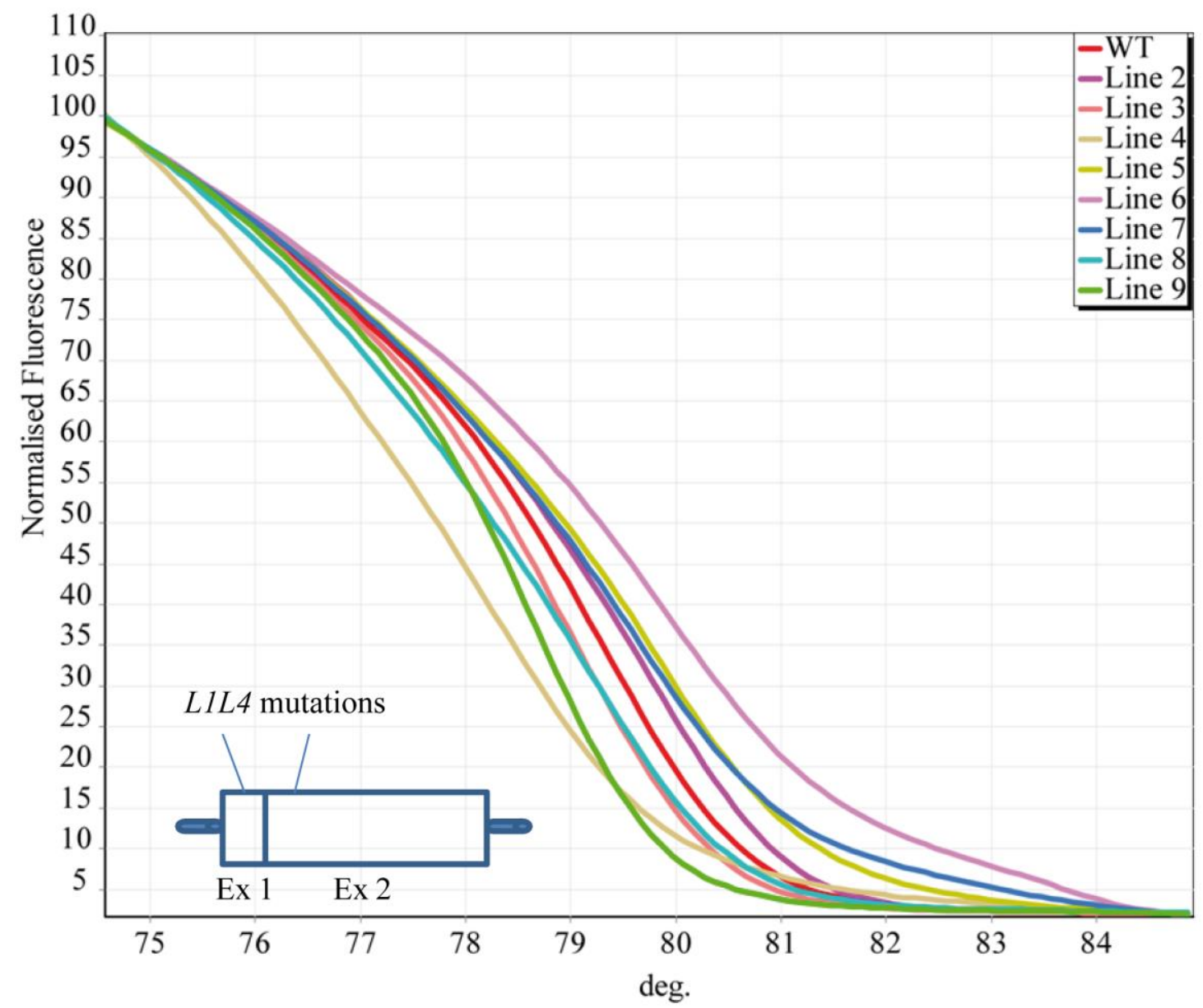

B

GCTATCGCAGATCTCCACAACCAACCCCTGCAGATCCCCCTrCCTCTGATGTGGAGATGAGCCTGGAACTGCCTGCACATCTCAACCAGGAAGT GCTATCGCAGATCTCCACAACCAACCCCTGCAGATCCCCCTrCCTCTGATGTGGAGATGAGCCTGAACCGCCATGCACATCTCAACCAGGAAGT GCTATCGCAGATCTCCACAACCAACCCCTGCAGATCCCCCTPCCT--GATGTGGAGATGAGCCTGGAACTGCCTGCACATCTCAACCAGGAAGT GCTATCGCAGATCTCCACAACCAACCCCTGCATATCCCCCTICCTCTGATGTGGAGATGAGCCTGGAACTGCCTGCACATCTCAACCAGGAAGT ATCGCAGATCTCCACAACCAACCCCTGCA (G) TATCCCCCTrCCTCTGATGTGGAGATGAGCCTGGAACTGCCTGCACATCTCAACCAGGAAGT GCTATCGCAGATCTCCACAACCAACCCCTGCAGATCCCCCTTCCTCTGATGTGGAGATGGAGCCTGGAACTGAC (A) (A) TGCACATCTCAACC GCTATCGCAGATCTCCACAACCAACCCCTGCAGATCCCCCTrCCTCTGATGTGGAGATGAGCCTGGAACTGCCTGCACATCTCAACCAGG (G) AAG 7 CAACCACCGCCAGCAGATCCCCCTTCCCCTGATG-GGAGGGGGGCC-GGAACTGCCAACACT-ATCAACCA CAACCA-CCCCTGCAG ( $T$ ) ATCCCCCTrCCTCTGATGTGGAGATGAGCCTGGAACTGCCTGCACATCTCAACCAGGAAGT

\section{Figure 1. Selection of lines carrying different single gene mutations}

(A) Mutation scanning at L1L4 locus using HRM analysis. A 131-bp fragment (exon 1 end - exon 2 beginning) was amplified from each cDNA sample of 8 ZFN-L1LA tomato lines of $\mathrm{M}_{4}$ generation and a wild-type background. Shown are the normalized temperature HRM curves (WT: red, line2: magenta, Line 3: orange, Line 4: beige, Line 5: olive, Line 6: pink, Line 7: blue, Line 8: cyan, Line 9: green). The eight different genotypes of $L 1 L 4$ gene at the specified region can be seen as curves with shape differences. (B) Genotypes of the L1L4 disruption lines. Target site sequences of wild type (WT) and mutant lines (2-9) are aligned. ZFN binding sites are shown in bold letters. A deletion is depicted with dash, an insertion with parenthesis and nucleotide change with red color. 


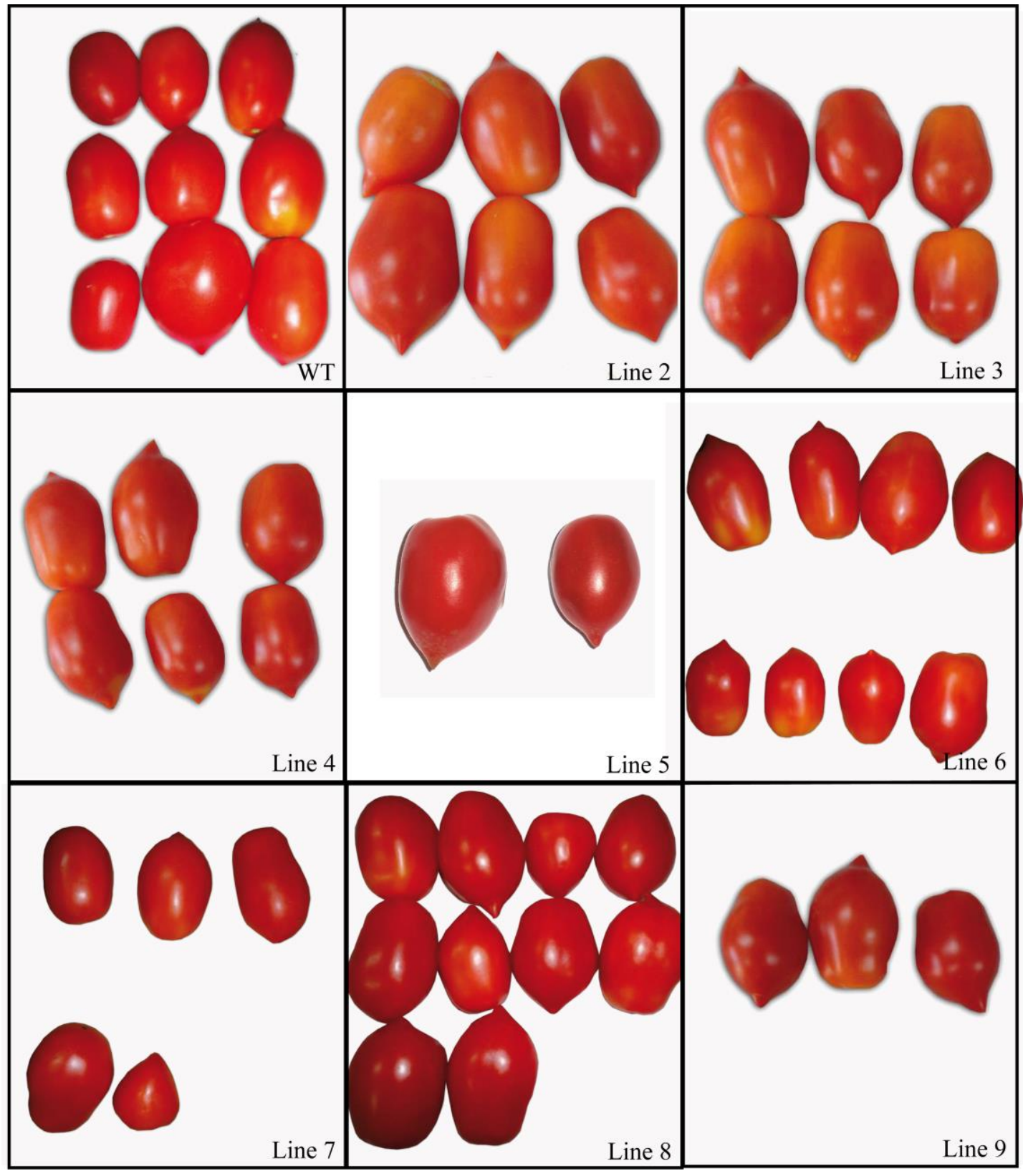

Figure 2. Tomato fruit phenotyping

Tomato fruit phenotypes from wild-type and $\mathrm{M}_{4} \mathrm{ZFN}-$ L1L4 lines. 


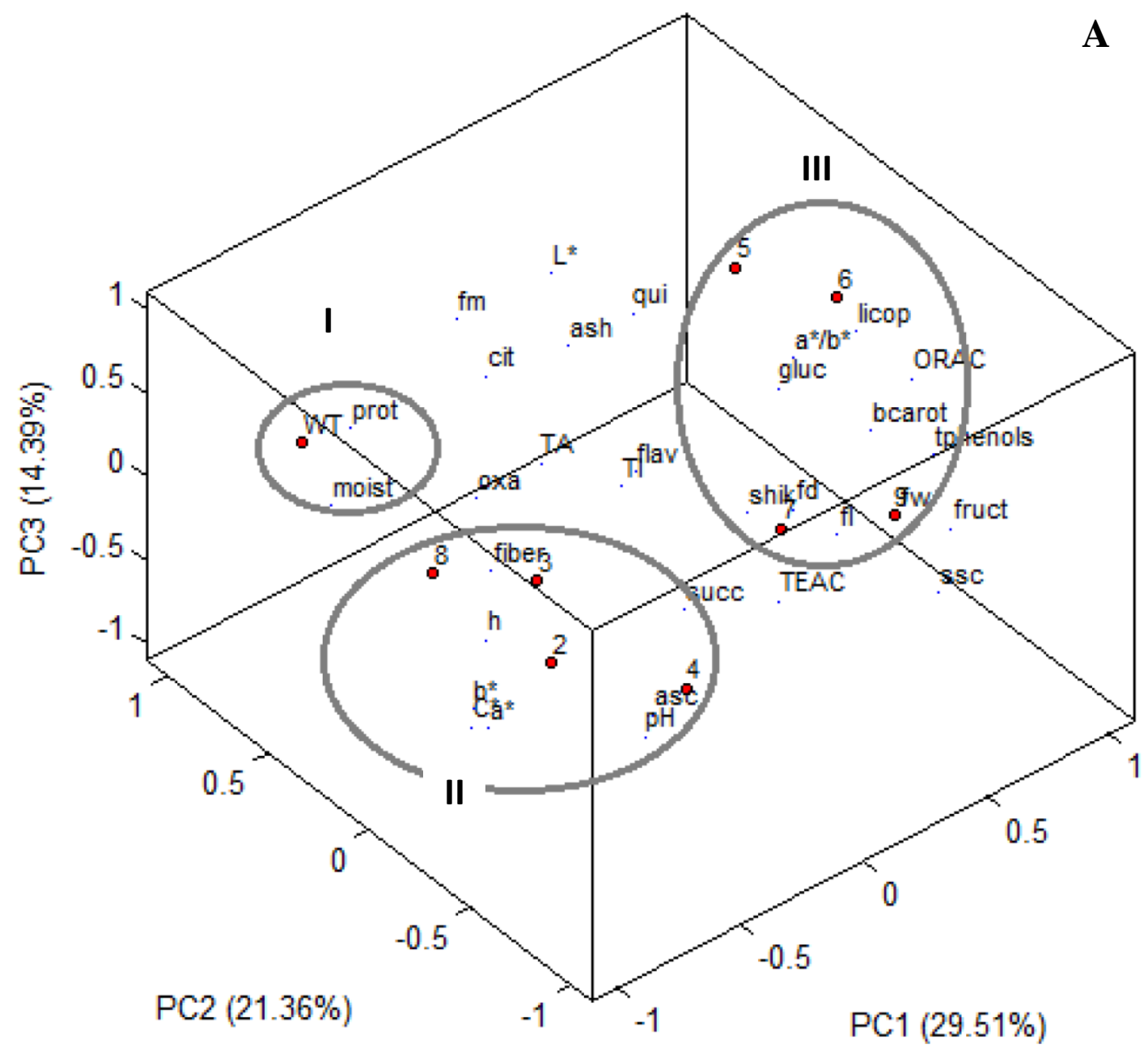




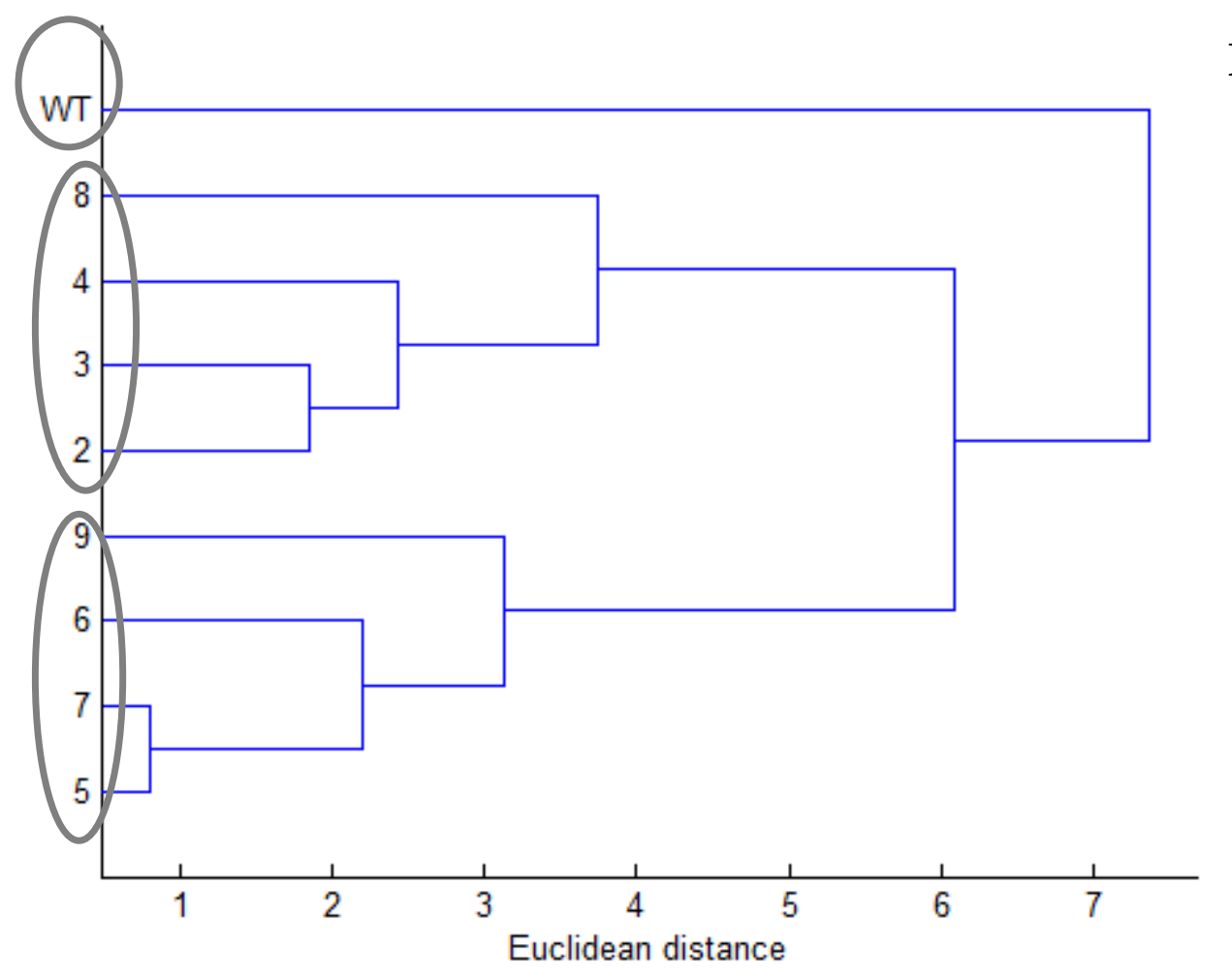

Figure 3. Principal component analysis of fruit quality parameters

(A) Scores and loading plot for PC1, PC2 and PC3 for wild-type tomato fruit and 8 L1L4 gene disruption lines. The percentage of total variance explained from each principal component is shown in parentheses. WT=wild-type; $2=$ line $2 ; 3=$ line 3 ; 4=line $4 ; 5=$ line; $6=$ line $6 ; 7=$ line $7 ; 8=$ line $8 ; 9=$ line $9 . a=a^{*}$ value; $b=b^{*}$ value; $C^{*}=$ chroma; $\mathrm{L}^{*}=$ lightness; $\mathrm{h}=$ hue angle; $\mathrm{fd}=$ fruit diameter; $\mathrm{fl}=$ fruit length; $\mathrm{fw}=$ fruit weight; $\mathrm{fm}=$ firmness, $\mathrm{TA}=$ titratable acidity; $\mathrm{TI}=$ taste index; moist=moisture; prot=protein; fruct=fructose; gluc=glucose; flav=flavonoids; licop=lycopene; bcarot $=\beta$-carotene; tphenols=total phenols content; asc=ascorbic acid; cit=citric acid; oxa=oxalic acid; qui=quinic acid; shik=shikimic acid; succ=succinic acid; TEAC=trolox equivalent antioxidant activity; ORAC $=$ oxygen radical absorbance capacity. (B) Dendogram of wild-type tomato fruit and $8 \mathrm{L1LA}$ gene disruption lines based on the measured quality and physicochemical variables. 

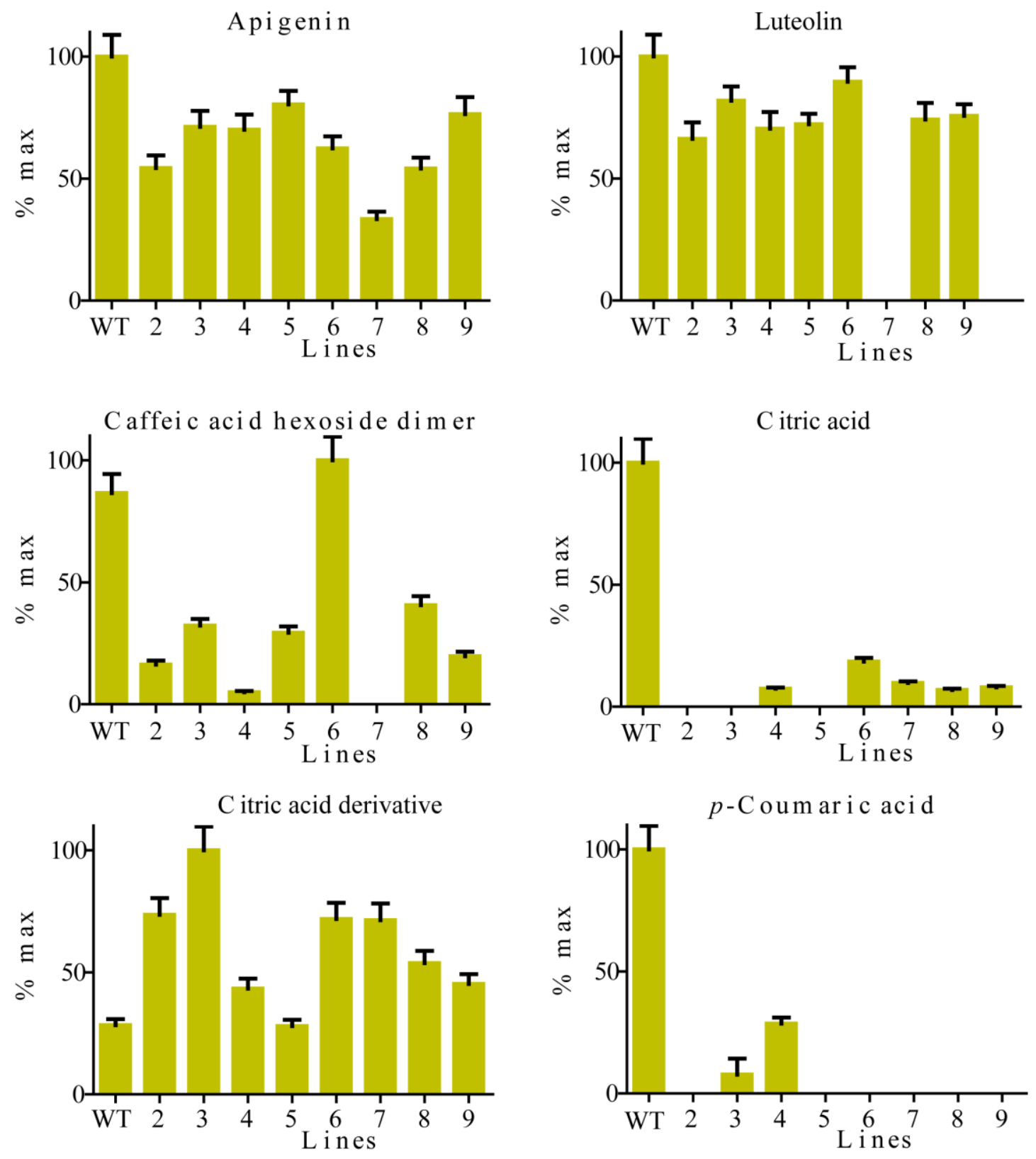

Homoveratric acid



Glucaric acid

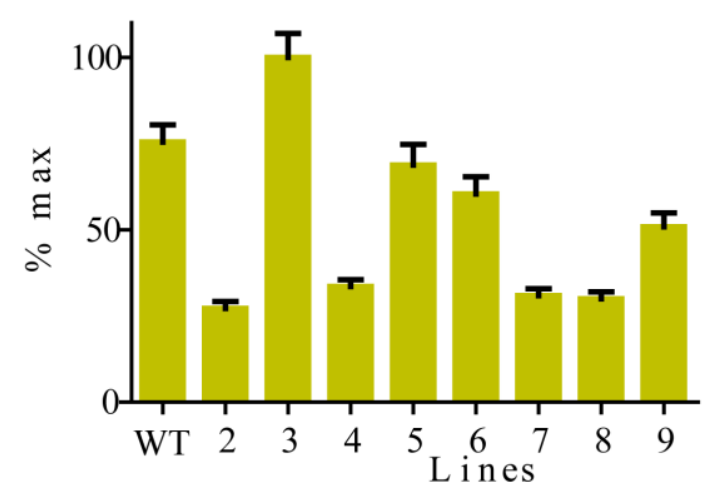

Figure 4. Seed metabolic profiling 
Metabolic profiles in tomato mature seeds from L1LA disruption lines and wild-type. Metabolites identified in mature seeds based on LC-MS/MS data. Relative amounts of metabolites in mature seeds from different mutant lines and wild-type background expressed as \% of the highest amount, which was set as '100'. Results are the means \pm SD. 


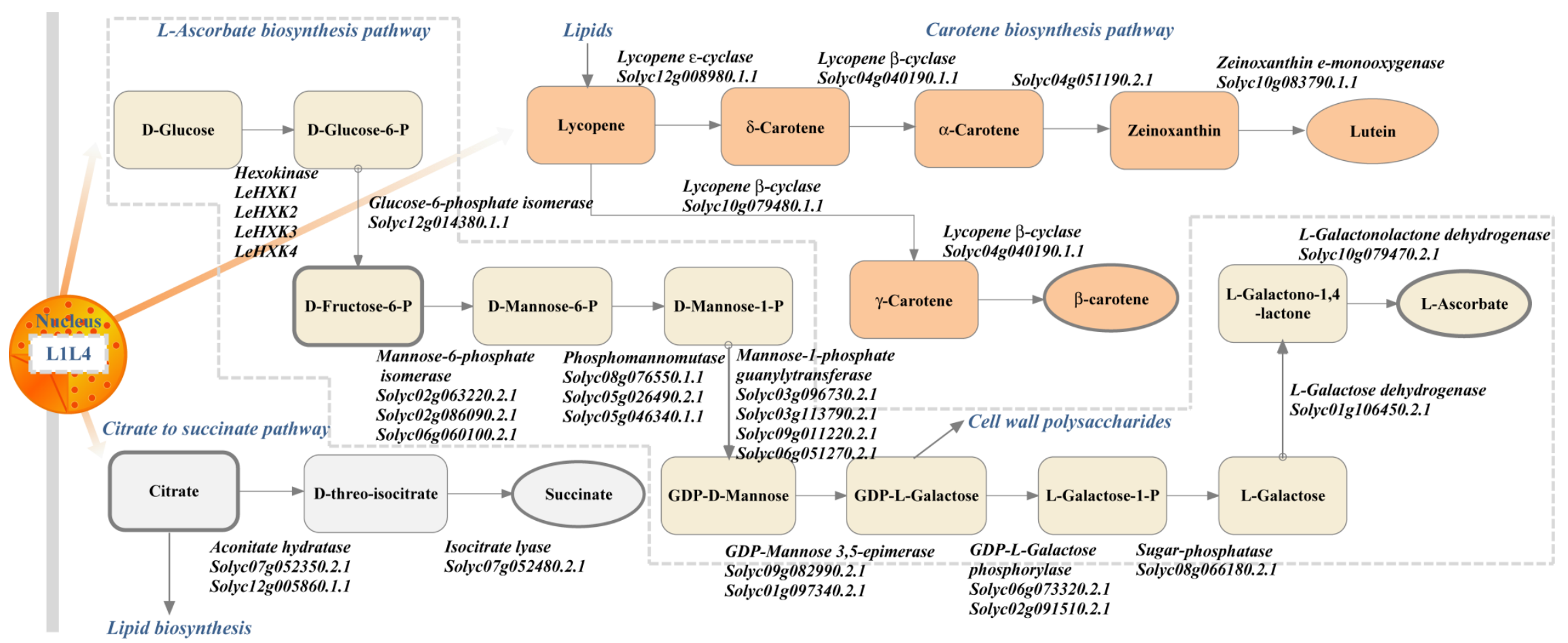

\section{Figure 5. In silico reconstruction of putative biosynthetic pathways}

Inference of putative metabolic pathways affected by L1L4 coding sequence disruption in lycopene, ascorbate and citrate biosynthesis. The predicted identities of genes encoding key enzymes in the metabolic pathways are shown. Key metabolites in each pathway are shown with squares and end products with circles. Significantly affected metabolites are shown with thick border. 
Electronic Supplementary Material

\section{Click here to access/download \\ Electronic Supplementary Material Supplemental File 1.docx}

